\title{
Exploring the role of MKK7 in excitotoxicity and cerebral ischemia: a novel pharmacological strategy against brain injury
}

\author{
A Vercelli ${ }^{1,2}$, S Biggi ${ }^{3}$, A Sclip ${ }^{3}$, IE Repetto ${ }^{1}$, S Cimini ${ }^{3}$, F Falleroni ${ }^{3}$, S Tomasi ${ }^{1}$, R Monti $^{1}$, N Tonna ${ }^{4}$, F Morelli ${ }^{3}$, V Grande ${ }^{1,3}$, M Stravalaci $^{3}$, \\ E Biasini ${ }^{3}, O$ Marin $^{5}$, F Bianco ${ }^{4,6}$, D di Marino ${ }^{7,8}$ and T Borsello*,3,9
}

Excitotoxicity following cerebral ischemia elicits a molecular cascade, which leads to neuronal death. C-Jun-N-terminal kinase (JNK) has a key role in excitotoxic cell death. We have previously shown that JNK inhibition by a specific cell-permeable peptide significantly reduces infarct size and neuronal death in an in vivo model of cerebral ischemia. However, systemic inhibition of JNK may have detrimental side effects, owing to blockade of its physiological function. Here we designed a new inhibitor peptide (growth arrest and DNA damage-inducible 45 $\beta$ (GADD45 $\beta$-I)) targeting mitogen-activated protein kinase kinase 7 (MKK7), an upstream activator of JNK, which exclusively mediates JNK's pathological activation. GADD45 $\beta$-I was engineered by optimizing the domain of the GADD45 $\beta$, able to bind to MKK7, and by linking it to the TAT peptide sequence, to allow penetration of biological membranes. Our data clearly indicate that GADD45 $\beta$-I significantly reduces neuronal death in excitotoxicity induced by either $N$-methyl-D-aspartate exposure or by oxygen-glucose deprivation in vitro. Moreover, GADD45 $\beta$-I exerted neuroprotection in vivo in two models of ischemia, obtained by electrocoagulation and by thromboembolic occlusion of the middle cerebral artery (MCAO). Indeed, GADD45 $\beta$-I reduced the infarct size when injected 30 min before the lesion in both models. The peptide was also effective when administrated $6 \mathrm{~h}$ after lesion, as demonstrated in the electrocoagulation model. The neuroprotective effect of GADD45 $\beta$-I is long lasting; in fact, 1 week after MCAo the infarct volume was still reduced by $49 \%$. Targeting MKK7 could represent a new therapeutic strategy for the treatment of ischemia and other pathologies involving MKK7/JNK activation. Moreover, this new inhibitor can be useful to further dissect the physiological and pathological role of the JNK pathway in the brain.

Cell Death and Disease (2015) 6, e1854; doi:10.1038/cddis.2015.226; published online 13 August 2015

In many disorders of the nervous system, overactivation of $\mathrm{N}$ methyl-D-aspartate (NMDA) receptors leads to neuronal death and consequent neurological impairment. NMDA-induced neuronal death, that is, excitotoxicity, has been implicated in many neurodegenerative diseases such as stroke, epilepsy, Alzheimer disease, spinal cord injury, traumatic brain injury, hearing loss, Parkinson's and Huntington diseases. ${ }^{1}$ However, the molecular mechanisms underlying excitotoxic neuronal death remain only partially understood.

Excitotoxicity triggers complex signal transduction events that induce the neuronal death program. Among them, activation of the c-Jun N-terminal kinase (JNK) pathway has a key role. ${ }^{2-5}$ There are only two direct upstream activators of JNK: mitogen-activated protein kinase kinase 4 and 7 (MKK4 and MKK7). ${ }^{6,7}$ In some cell types, MKK4 activates JNK primarily in response to stress stimuli, whereas MKK7 signaling is triggered by release of inflammatory cytokines. $^{8-10}$ In neurons, however, we showed that MKK7 is mainly responsible for JNK overactivation during excitotoxicity both in vitro ${ }^{3}$ and in vivo following middle cerebral artery occlusion (MCAo). ${ }^{4}$ Conversely, MKK4 controls JNK physiological role and its activation is not affected by excitotoxic stimuli. ${ }^{3}$

Inhibition of the JNK pathway by the specific JNK inhibitor peptide, D-JNKI1, has been proposed for the treatment of ischemia. $^{2}$ D-JNKI1 induces powerful neuroprotection in in vitro models of excitoxicity ${ }^{2,11}$ and leads to a $93 \%$ reduction in the infarct size in rodent models of ischemia. ${ }^{2,4,12}$ Despite the potent and long-lasting neuroprotective effect of D-JNKI1, total inhibition of JNK is not deprived of negative side effects, as it regulates a variety of physiological events ${ }^{13}$ such as cell proliferation, survival and differentiation. ${ }^{13}$ For these reasons, MKK7 may represent a more attractive target for clinical

\footnotetext{
${ }^{1}$ Department of Neuroscience, NICO - Neuroscience Institute Cavalieri Ottolenghi, Neuroscience Institute of Turin (NIT), University of Turin, Turin I-10125, Italy; ${ }^{2}$ National Institute of Neuroscience, Corso Raffaello 30, Turin, Italy; ${ }^{3}$ Neuronal Death and Neuroprotection Laboratory, IRCCS - Istituto di Ricerche Farmacologiche, 'Mario Negri', Via La Masa 19, Milan 20156 Italy; ${ }^{4}$ Sanipedia, Via Ariosto 21, Bresso (MI) 20091, Italy; ${ }^{5}$ Department of Biomedical Sciences, University of Padova, Padova 35121 , Italy; ${ }^{6}$ Fondazione Fernando Santarelli, Neuroinflammation Lab, Corso Venezia 18, Milan, Italy; ${ }^{7}$ Department of Physics, Sapienza University of Rome, Rome, Italy; ${ }^{8}$ Department of Chemistry, Brooklyn College, City University of New York, Brooklyn, New York, USA and ${ }^{9}$ Department of Pharmacological and Biomolecular Sciences, University of Milan, Milan, Italy

*Corresponding author: T Borsello, Neuronal Death and Neuroprotection Laboratory, IRCSS - Istituto Di Ricerche Farmacologiche, 'Mario Negri', Via la Masa 19, Milano 20156 Italy. E-mail: tiziana.borsello@marionegri.it or Department of Pharmacological and Biomolecular Sciences, Università degli Studi di Milano Via Balzaretti 9 , Milano 20133, Italy. Tel: +39 338882 8123; Fax: +39 023900 1916; E-mail: tiziana.borsello@ unimi.it

Abbreviations: JNK, c-Jun-N-terminal kinase; GADD45 $\beta$, growth arrest and DNA damage-inducible 45 $\beta$; MKK7, mitogen-activated protein kinase kinase 7; MKK4, mitogen-activated protein kinase kinase 4; MCAo, middle cerebral artery occlusion; NMDA, N-methyl-D-aspartate; OGD, oxygen-glucose deprivation; SPR, surface plasmon resonance

Received 20.2.2015; revised 25.6.2015; accepted 08.7.2015; Edited by A Yaron
} 
application, as it activates JNK specifically after toxic stimuli. Thus, by targeting MKK7 the physiological role of JNK, regulated by MKK4, will be preserved.

Here we designed a set of new cell-permeable inhibitor peptides able to block MKK7 activity and protect against excitotoxic death.

We took advantage of the growth arrest and DNA damageinducible $45 \beta$ (GADD45 $\beta$ ) ability to bind MKK7. ${ }^{9,14,15}$ GADD45 $\beta$ is involved in the control of cell stress responses in cell cycle, DNA repair and oncogenesis. ${ }^{9,16}$ GADD45 $\beta$ binds tightly to MKK7 and inhibits its enzymatic activity ${ }^{15}$ by interacting with its catalytic domain. ${ }^{9}$ More importantly, GADD45 $\beta$ inhibition is MKK7-specific and has no effect on MKK4, MKK3/6 and MEK1/2 activity. ${ }^{9}$ The minimal essential domain of interaction between MKK7 and GADD45 $\beta$ has already been defined (GADD45 $\beta_{60-86}$ and ${ }_{69-86}$ sequences). ${ }^{15}$ We here used in silico approaches to design an effector peptide, based on the domain of GADD45 $\beta$, and optimize its affinity for MKK7. We then linked the effector peptide to a TATcargo in order to penetrate neuronal plasma membrane. ${ }^{17}$ The selected cell-permeable MKK7 inhibitor peptide (GADD45 $\beta$-I) confers neuroprotection in vitro against NMDA and oxygenglucose deprivation (OGD) toxicity, as well as in vivo in two models of MCAo with a clinically relevant post-ischemic temporal window $(6 \mathrm{~h})$ at both $24 \mathrm{~h}$ and 1 week after lesion. These data shed light on a new approach for the treatment of ischemia.

\section{Results}

Design and development of TAT-MKK7 inhibitor peptides: GADD45 $\beta$-I. The minimal essential region of GADD $45 \beta$ that interacts with MKK7 is at residues $60-86$, but another region (residues 104-113) seems to have a more marginal role to stabilize the interaction between GADD45 $\beta$ and MKK7 (Papa et $a .^{15}$ ) (Figure 1a). As shown in Figure 1a, reporting the structure of GADD $45 \beta$ obtained by homology modeling, residues $60-86$ form a helix-turn motif (Figure $1 \mathrm{~b}$ ). Most of the residues in this region are hydrophilic and residues 62-68 are all negatively charged. Residues 104-113 form a long loop with an alternation of hydrophilic and negative residues (Figure 1b), and its marginal role in the GADD45 $\beta-$ MKK7 protein-protein interaction is probably due to the highly flexible nature of this portion of GADD45 $\beta$.

GADD45 $\beta$ interacts with MKK7 in proximity of its ATPbinding site $^{9}$ and this may justify the presence of acidic residues able to establish electrostatic interactions with the basic residues in this site. ${ }^{9}$

The docking results put in evidence that in the majority of the complexes obtained, region $60-86$ is able to interact with MKK7 (Figure 1a), matching the experimental data already available. ${ }^{9,14,15}$ In detail, the $\alpha$-helix of GADD $45 \beta$ establishes a network of hydrogen bonds with the $\beta$-sheets forming the MKK7 ATP-binding site (Figure 1a). The negatively charged residues following GADD $45 \beta a$-helix interact through a cluster of electrostatic interactions with the positively charged residues of MKK7 (Figure 1a).

These pieces of information were used to design two peptides able to interact with MKK7 and inhibiting its function.
The first peptide (GADD45 $\beta_{69-86}$ ) was designed by considering only the sequence of the $\alpha$-helix (residues 69-86) and avoiding the cluster of negative residues (Figure 1c).

Consistently with in silico prediction, GADD45 $\beta_{69-86}$ showed an affinity in the low micromolar range for recombinant MKK7 in vitro, as assayed by surface plasmon resonance (SPR, Figure 2). Of note, the measured binding affinity $(3.71 \mu \mathrm{M})$ of the GADD45 $\beta_{69-86}$ peptide for recombinant MKK7 was in good agreement with the biologically relevant concentrations observed in subsequent experiments. The TAT sequence was then been added to the $\mathrm{N}$-terminal region of the peptide (Figure 1c). A second peptide (TAT-GADD45 $\beta_{60-86}$ ) was designed by considering all the regions formed by residues 60-86 (Figure 1d). As previously stated, residues 62-68 are all negatively charged and they could have a key role in stabilizing the interaction. However, this peptide showed poor solubility in water. To avoid the interaction between the negatively charged residues in the effector and the positively charged amino acids of the TAT peptide, a spacer sequence was added between the peptide and the TAT (TAT-spacer-GADD45 $\beta_{60-86}$ ) (Figure 1d). To validate the specificity of TAT-GADD45 $\beta_{69-86}$ and TAT-spacerGADD $45 \beta_{60-86}$ peptides we designed a control peptide, TATGADD $45 \beta_{60-86}$ CONTROL, where 17 residues out of 27 composing the GADD45 $\beta_{60-86}$ peptide were changed. In detail, the control peptide was obtained by substituting all the negative charges with alanine residues (Figure 1d). Moreover, to achieve a complete inhibition of interaction with MKK7, we made the peptide less specific as possible by also mutating in alanine or glycine the amino acids with physical-chemical characteristics that could have a cooperative effect on the binding (Figure 1c; i.e., Gln, His, Phe, Thr and Cys, and Figure 1d). Based on these predictions, the control peptide TAT-GADD45 $\beta_{60-86}$ CONTROL was designed in order to be an inactive peptide.

Effect of GADD45 $\beta$ - I peptides on cultured neurons. The cell-permeable MKK7 inhibitor peptides were tested in primary cultures from dissociated cortical neurons. Toxicity of the peptides was assessed after $24 \mathrm{~h}$ with LDH assay. Application of both TAT-GADD $45 \beta_{69-86}$ and TAT-spacerGADD45 $\beta_{60-86}$ peptides did not induce neuronal death for concentrations as high as $10 \mu \mathrm{M}$ (one-way ANOVA, $P>0.05$ ) (Figure 3a). Conversely, the control (5'-AIAAAAAAAIALGIGA GLIGSAAGNGAGAGAAGRKKRRQRRR-3') peptide, TATGADD $45 \beta_{60-86}$ CONTROL application for $24 \mathrm{~h}$ resulted in an increase of neuronal death at the higher dosages (5 and $10 \mu \mathrm{M}$ ) (not shown, one-way ANOVA, Tukey's post-hoc test, *** $P<0.001)$.

NMDA neurotoxicity and neuroprotection by GADD45 $\beta$ - I peptides. The TAT-GADD45 $\beta_{69-86}$, the TAT-spacerGADD $45 \beta_{60-86}$ and the TAT-GADD45 $\beta_{60-86}$ conTROL peptides were tested against NMDA toxicity in vitro. Addition of the cell-penetrating GADD $45 \beta$ - I peptides at the concentration of $1,2.5$ and $5 \mu \mathrm{M}$ protected neurons against excitotoxicity induced by exposure to $100 \mu \mathrm{M}$ NMDA for $6 \mathrm{~h}$ (Figure $3 \mathrm{~b}$ ). In fact, the TAT-GADD $45 \beta_{69-86}$ peptide exerts a $65 \%$ protection against NMDA insult at $2.5 \mu \mathrm{M}$ concentration, whereas the TAT-spacer-GADD45 $\beta_{60-86}$ peptide protects by 53,64 and 


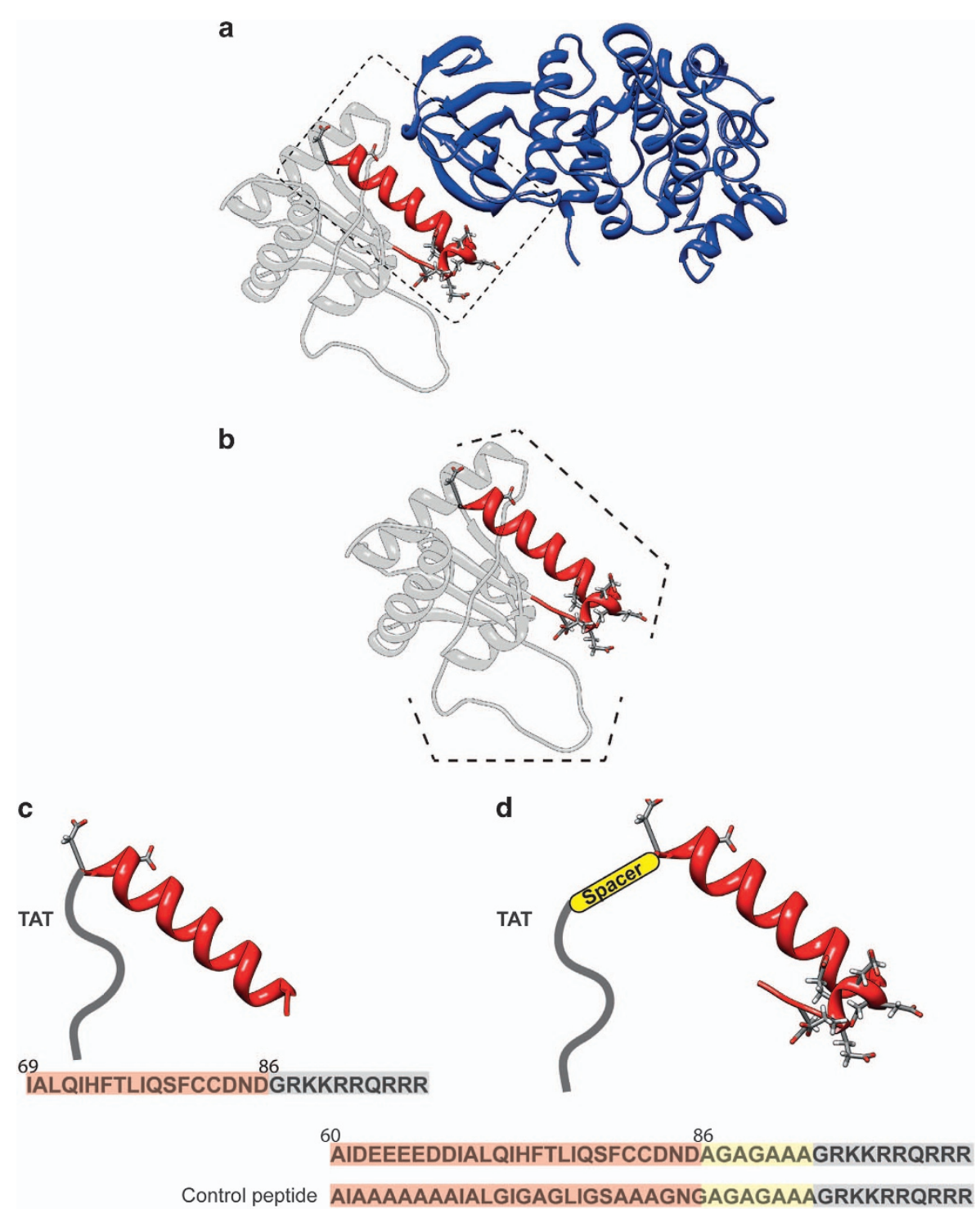

Figure 1 Design of specific inhibitors of MKK7 based on GADD45 $\beta$ structure. (a) Ribbon representation of the best complex resulting from the docking between the modeled structure of GADD $45 \beta$ and MKK7. MKK7 is shown in blue and GADD $45 \beta$ in gray. The helix-turn motif of GADD $45 \beta$ involved in the interaction, taken as a template to design the peptides, has been reported in red. (b) Structure of GADD $45 \beta$ protein obtained by homology modeling. Residues $60-86$ forming a helix-turn motif are highlighted in red and with a dashed line. Residues 104-113 form a long loop with an alternation of hydrophilic and negative residues, this region is highlighted with a dashed line. (c) Modeling of TATGADD45 $\beta_{69-86}$ peptide. In red is the sequence of the $\alpha$-helix (residues 69-86) and in gray the sequence of TAT. The entire sequence of the peptide is shown on the bottom. (d) Modeling of TAT-spacer-GADD45 $\beta_{60-86}$ peptide. In red is showed the sequence of the the $\alpha$-helix (residues 60-86), in yellow the position of the linker and in gray the TAT sequence. The entire sequence of the peptide is shown on the bottom. The sequence of the TAT-GADD $45 \beta_{69-86}$ CONTROL is also reported

$125 \%$ at $1,2.5$ and $5 \mu \mathrm{M}$, respectively (one-way ANOVA, Tukey's post-hoc test, ${ }^{* * *} P<0.001$ NMDA versus CTR, $\# P<0.05$ NMDA+MKK7I versus NMDA, \#\#P<0.01 NMDA + MKK7I versus NMDA and \#\#\#P<0.001 NMDA+MKK7I versus NMDA) (Figure $3 \mathrm{~b}$ ). Similar results were obtained after $12 \mathrm{~h}$ of NMDA exposure (Figure $3 \mathrm{~b}$ ). In this case, both TAT-GADD45 $\beta_{69-86}$ and TAT-spacer-GADD45 $\beta_{60-86}$ peptides lead to a significant protection of 59 and $56 \%$, respectively, at the higher dose tested $(5 \mu \mathrm{M})$ (one-way ANOVA, Tukey's post-hoc test, ${ }^{* * *} P<0.001$ NMDA versus $\mathrm{CTR}, \# P<0.05$ NMDA+MKK7I versus NMDA and \#\#\#P<0.001 NMDA +MKK7I versus NMDA). As expected TAT-GADD45 $\beta_{60-86}$ CONTROL peptide showed no protection for all the concentrations tested $(1,2.5$ and $5 \mu \mathrm{M})$ and both time points
(6 and $12 \mathrm{~h}$ ) (Supplementary Figure S1, one-way ANOVA, $P>0.05)$. Thus, the protective effect of the TAT-GADD $45 \beta_{69}$ ${ }_{86}$ peptides is entirely accountable to the peculiar amino acids composition of the region between residues $69-86$ of the GADD45 $\beta$ protein.

Out of the two peptides tested, TAT-spacer-GADD45 $\beta_{60-86}$ resulted as the most efficient in preventing NMDA excitotoxicity. Therefore, we decided to use this peptide for the following experiments. We tested TAT-spacer-GADD45 $\beta_{60-86}$ in an in vitro model of OGD. TAT-spacer-GADD45 $\beta_{60-86}$ $(5 \mu \mathrm{M})$ inhibited by $95 \%$ the neuronal death induced by $12 \mathrm{~h}$ OGD (one-way ANOVA, Tukey's post-hoc test, ${ }^{* *} P<0.01$ OGD versus $\mathrm{CTR}$ and \#\#P<0.01 OGD+MKK7I versus OGD) (Figure 3c). 


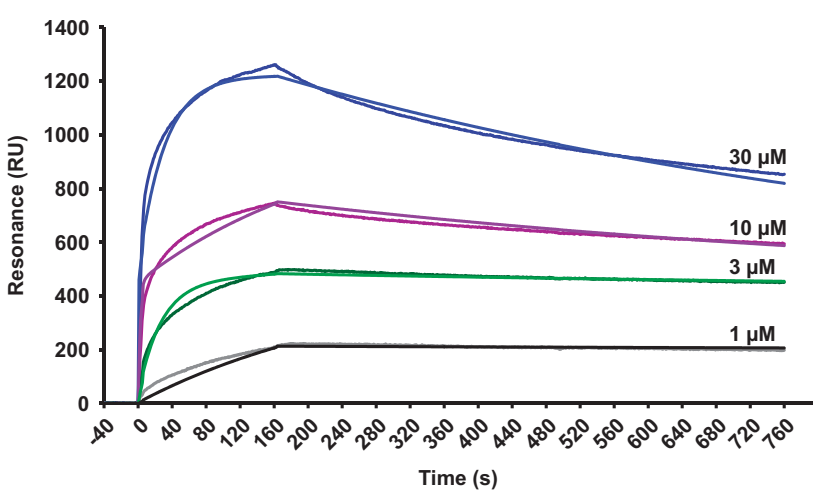

Figure 2 GADD $45 \beta_{69-86}$ interacts with recombinant MKK7. Starting at time 0 , the indicated concentrations of GADD $45 \beta_{69-86}$ were injected for $150 \mathrm{~s}$ over SPR sensor surfaces on which 5000 RUs of human recombinant MKK7 had been previously captured by amine coupling. The SPR chip was then washed with buffer alone to monitor ligand dissociation. Fitted sensorgrams show GADD $45 \beta_{69-86}$ binding to recombinant MKK7 in RUs. The data were obtained by subtracting the reference channels, containing bovine serum albumin or no polypeptides. The heterogenous ligand equation was the best algorithm to fit the data, suggesting that recombinant MKK7 was immobilized in different orientations on the chip surface. Binding parameters obtained in this manner were as follows: $k_{\text {on }}=3.15 \times 10^{2} 1 / \mathrm{Ms}$; $k_{\text {off }}=1.30 \times 10^{-3} 1 / \mathrm{s} ; K_{\mathrm{D}}=3.71 \mu \mathrm{M}$

Efficacy and specificity of GADD45 $\beta$ - I peptides. We tested the specificity of the TAT-spacer-GADD45 $\beta_{60-86}$ peptide for MKK7. Application of NMDA for 5, 30 and 60 min triggers MKK7 activation in neurons ${ }^{3}$ by increasing its phosphorylation by 1.7-, 1.5- and 1.9-fold, respectively, confirming its pivotal role in excitotoxicity (two-way ANOVA, Tukey's post-hoc test, ${ }^{*} P<0.05$ CTR versus NMDA and ${ }^{\star * \star} P<0.001$ CTR versus NMDA) (Figure 4a). Treatment with the TAT-spacer-GADD45 $\beta_{60-86}$ peptide abolishes MKK7 phosphorylation in cortical neurons, inhibiting the kinase activity after either 5, 30 or 60 min of NMDA application by 78, 146 and 64\%, respectively (two-way ANOVA, Tukey's post-hoc test, \#\#P<0.01 MKK7I+NMDA versus NMDA) (Figure 4a). On the contrary, NMDA application does not affect MKK4 activation and treatment with TAT-spacerGADD45 $\beta_{60-86}$ peptide has no effect on MKK4 pathway (two-way ANOVA, interaction >0.05) (Figure 4b).

MKK7 inhibition is protective in two in vivo models of cerebral ischemia. The TAT-spacer-GADD45 $\beta_{60-86}$ inhibitor peptide (referred as GADD45 $\beta$ - I) was tested in the MCAo and the thromboembolic ischemia model in rats.

MCAo model: We used this ischemic model to perform most of the experiments. Two different paradigms of GADD45 $\beta-$ I administration were chosen as follows: (1) $30 \mathrm{~min}$ before (pre-ischemic injection) and (2) $6 \mathrm{~h}$ after cerebral ischemia (clinical setting). Infarct area measurements were performed on 2,3,5-triphenyltetrazolium chloride (TTC)-stained brain slices $24 \mathrm{~h}$ after ischemia. In all animals, MCAo affected the right frontoparietal cortex areas, as well as the underlying striatum, even though moderately (Figure 5a). Pre-ischemic injection of GADD $45 \beta-1$ reduced the infarcted volume by $43 \%$ (Figures $5 b-d)$. In fact, the percentage of ischemic volume on the whole rat brain (mean \pm s.d.) was $7.85 \pm 2.03 \%$ in the
GADD45 $\beta$ - I-treated group $(n=6)$ versus $13.72 \pm 4.07 \%$ in control rats $(n=5)\left({ }^{\star \star} P<0.01\right.$; Figures $\left.5 b-d\right)$.

To define the therapeutic window of this inhibitor peptide, we injected GADD45 $\beta$ - I 6 and $12 \mathrm{~h}$ after induction of MCAo. Injection of GADD $45 \beta$ - I 6 h post ischemia reduced the infarct volume by $42 \%$, indicating a strong protection and a great potential of GADD $45 \beta$ - I treatment (Figures $5 c$ and d). In this case, the percentage of ischemic volume in GADD45 $\beta-1-$ treated rats injected $6 \mathrm{~h}$ post lesion was $8.04 \pm 1.04 \%(n=5)$ $\left({ }^{* *} P<0.01\right.$; Figures $5 \mathrm{c}$ and d). On the contrary, the 12-h postischemic injection of GADD $45 \beta-1$ did not significantly decrease the infarct volume, indicating the failure of protection at this time point (not shown). Significant reduction in infarct size was maintained 1 week after MCAo, when pre-ischemic administration of GADD $45 \beta$ - I reduced the infarct volume by almost $50 \%$ (Figures $5 \mathrm{e}$ and $\mathrm{f}$ ). The percentage of ischemic volume was $6.22 \pm 0.98 \%$ in the GADD $45 \beta$ - l-treated group $(n=5)$ versus $12.42 \pm 2.22 \%$ in control rats $(n=5)\left({ }^{* *} P<0.01\right.$; Figures $5 \mathrm{f}-\mathrm{h})$. Injection of GADD $45 \beta-\mathrm{I} 6 \mathrm{~h}$ post ischemia reduced the infarct volume by $44 \%$ (Figures $5 \mathrm{e}-\mathrm{g}$ ). In this case, the percentage of ischemic volume in GADD $45 \beta-\mathrm{I}$ treated rats injected $6 \mathrm{~h}$ post lesion was $6.95 \pm 0.93 \%(n=5)\left({ }^{\star \star} P<0.01\right.$; Figures $5 \mathrm{~g}$ and $\left.\mathrm{h}\right)$.

MKK7-mediated neuroprotection: mechanism of action. To validate the GADD45 $\beta$ - I action mechanism we characterized MKK7 activation, evaluated as P-MKK7/MKK7 ratio, in ischemic tissues from control and GADD45 $\beta-1-$ treated MCAo animals at 3 and $6 \mathrm{~h}$ after ischemia. As previously reported, MKK7 phosphorylation increased in the ipsilateral hemisphere after ischemia at 3 and $6 \mathrm{~h}$, suggesting an early activation. ${ }^{4}$ Treatment with GADD $45 \beta$ - I conferred a $43 \%$ protection on infarct size, which correlated with MKK7 inhibition in treated animals compared with MCAo: in fact, rats treated with GADD $45 \beta$ - I showed a $54 \%$ reduction of $\mathrm{P}-\mathrm{MKK} 7 / \mathrm{MKK} 7$ ratio $3 \mathrm{~h}$ after ischemia (two-way ANOVA, Tukey's post-hoc test, ${ }^{\star} P<0.05$ ) (Figure 6a), which persisted $6 \mathrm{~h}$ after ischemia (33\% reduction of $\mathrm{P}-\mathrm{MKK} 7 / \mathrm{MKK} 7$ ratio; two-way ANOVA, Tukey's post-hoc test, ${ }^{*} P<0.05$ ) (Figure $6 b$ ). To clarify the neuroprotective mechanism of GADD $45 \beta-1$ we analyzed the levels of JNK $6 \mathrm{~h}$ post ischemia. At $6 \mathrm{~h}$, ischemic injury leads to a pathological activation of JNK, which was reduced by application of GADD45 $\beta-1$ (Figure 6c). To verify the specificity of GADD45 $\beta$ - I for the MKK7-JNK pathway, we also analyzed the phosphorylation level of MKK4: treatment with GADD45 $\beta$ - I induces a modest, but not significant, increase in the basal activity of MKK4 (Figure $6 \mathrm{~d}$ ). These results suggest that GADD45 $\beta-1$ specifically inhibits MKK7 pathway, without blocking MKK4, and this inhibition leads to a significant neuroprotection in vivo, with a temporal intervention window of $6 \mathrm{~h}$ after cerebral ischemia.

Thromboembolic ischemia model: To confirm the neuroprotective role of GADD $45 \beta-1$ in vivo, we used a second ischemic model. In this model, the GADD $45 \beta$ - I peptide was injected $30 \mathrm{~min}$ before the induction of ischemia. Rats treated with GADD $45 \beta$ - I showed significant improvements of the functional neuroscore $24 \mathrm{~h}$ after ischemia compared with the control group. Furthermore, TTC staining showed that rats 

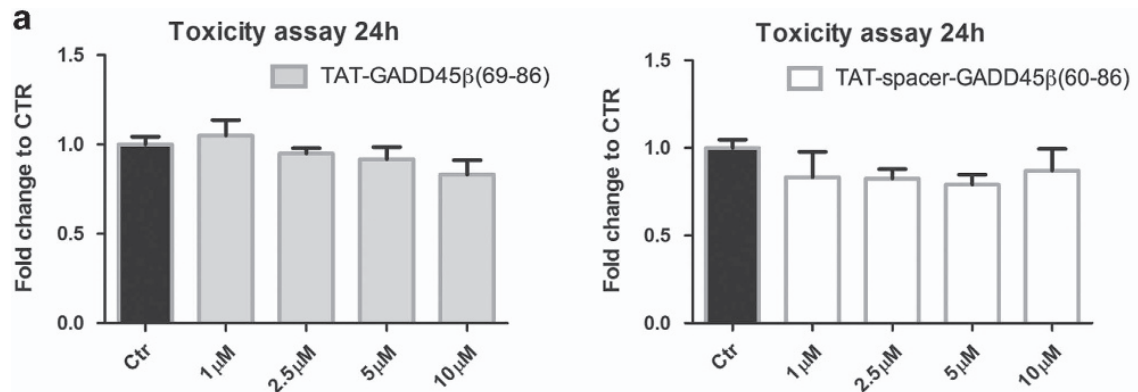

b

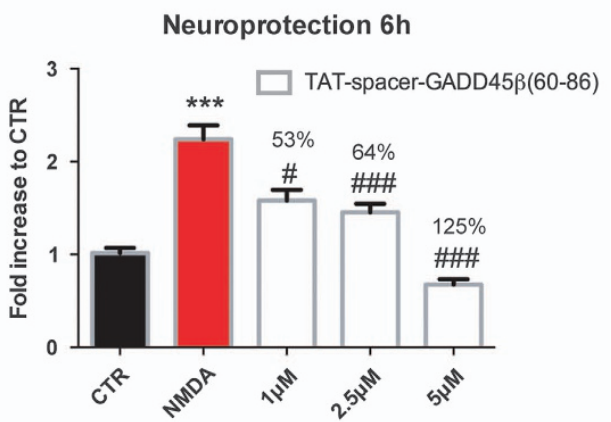

Neuroprotection $12 \mathrm{~h}$
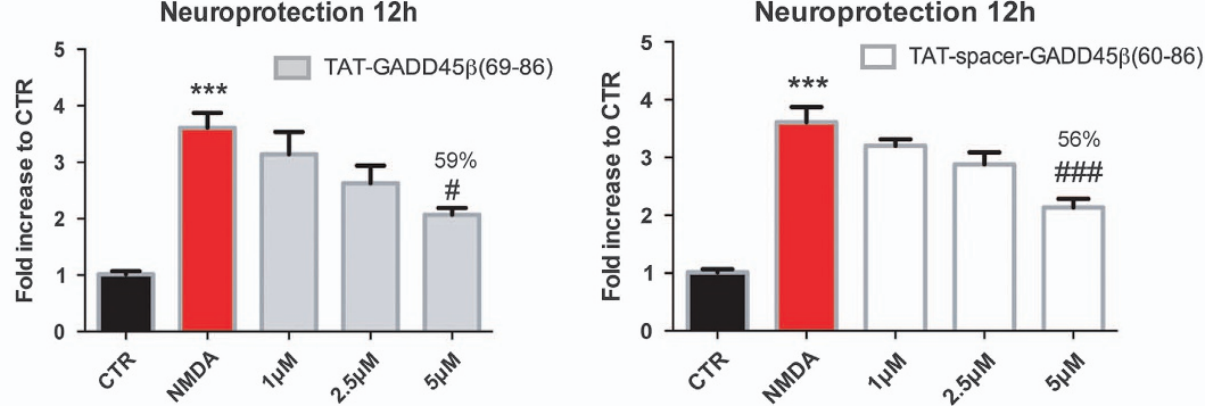

C

OGD $12 \mathrm{~h}$

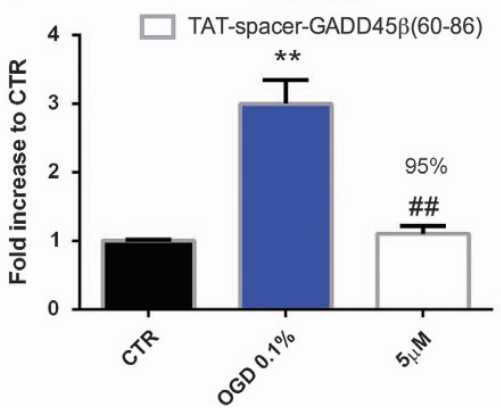

Figure 3 TAT-GADD45 $\beta_{69-86}$ and TAT-spacer-GADD45 $\beta_{60-86}$ do not induce neuronal death and protect neurons from NMDA and OGD insults. (a) LDH assay to assess intrinsic toxicity of MKK7 inhibitor peptides. Twelve DIV cortical neurons were treated with increased concentrations (1, 2.5, 5 and $10 \mu \mathrm{M}$ ) of TAT-GADD45 $\beta_{69-86}$ (left) and TATspacer-GADD $45 \beta_{60-86}$ (right) for $24 \mathrm{~h}$. Data are presented as mean \pm S.E.M. (one-way ANOVA, $P>0.05, n=8$ ). (b) LDH assay was performed on 12 DIV cortical neurons to evaluate the ability of TAT-GADD45 $\beta_{69-86}$ (left) and TAT-spacer-GADD45 $\beta_{60-86}$ (right) peptides (1,2.5 and $5 \mu \mathrm{M}$ ) to protect against $100 \mu \mathrm{M}$ NMDA-induced excitotoxicity in vitro for 6 (upper panels) and $12 \mathrm{~h}$ (lower panels). Data are presented as mean \pm S.E.M. (one-way ANOVA, Tukey's post-hoc test, ${ }^{* * *} P<0.001$ NMDA versus CTR, ${ }^{\#} P<0.05$ NMDA + MKK7I versus NMDA, ${ }^{\#} P<0.01$ NMDA+MKK7I versus NMDA, ${ }^{\# \#} P<0.001$ NMDA+MKK7I versus NMDA, $n=6$ ). (c) LDH assay to evaluate the ability of TAT-spacerGADD $45 \beta_{60-86}$ peptide pre-treatment ( $5 \mu \mathrm{M}, 30$ min before OGD) to protect against $12 \mathrm{~h} \mathrm{OGD}$. Data are presented as mean \pm S.E.M. (one-way ANOVA, Tukey's post-hoc test, ${ }^{* *} P<0.01$ OGD versus CTR, ${ }^{\# \#} P<0.01$ OGD+MKK7I versus OGD, $n=6$ ) 
a
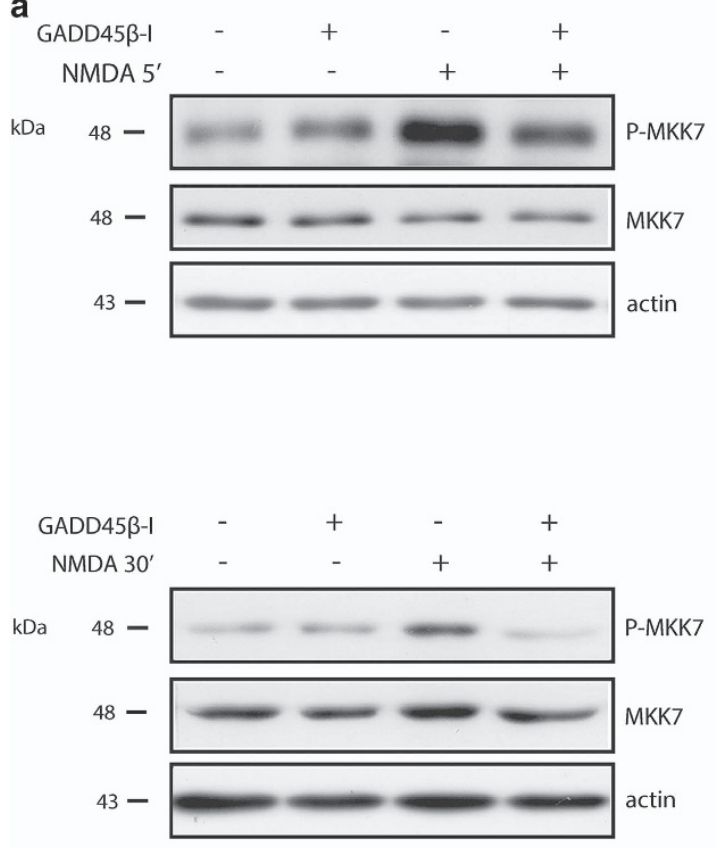

GADD45ß-I $\quad-\quad+\quad+\quad+\quad+$

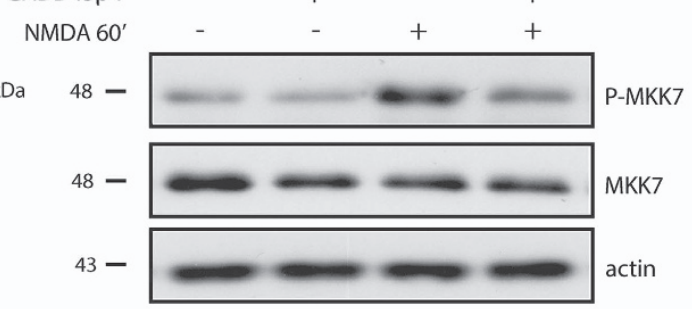

P-MKK7/MKK7 5'

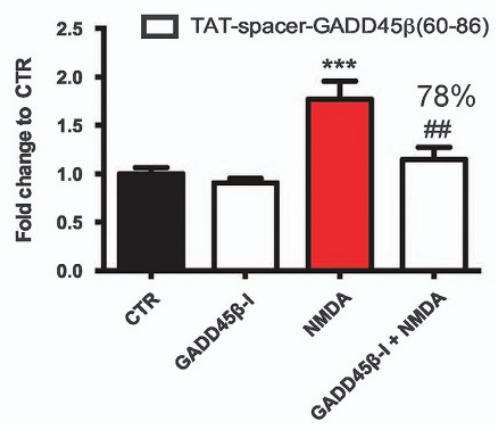

P-MKK7/MKK7 30'

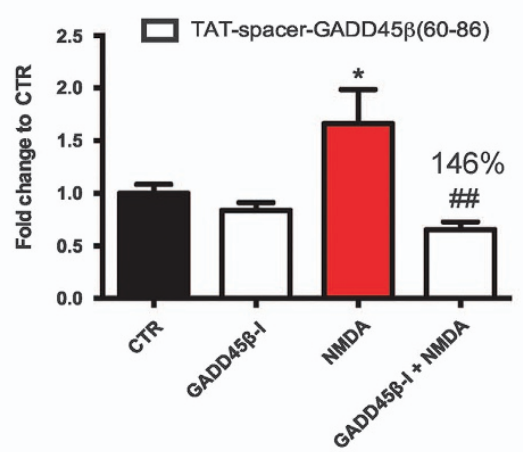

P-MKK7/MKK7 60'

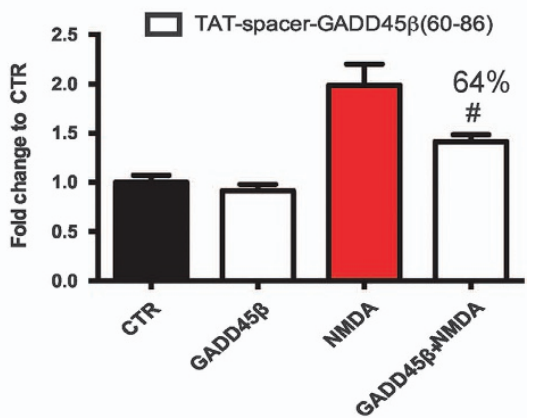

Figure 4 TAT-spacer-GADD45 $\beta_{60-86}$ peptide specifically prevents NMDA-induced MKK7 activation without interfering with MKK4 pathway. (a) Western blotting and relative quantification of P-MKK7/MKK7 ratio in 12 DIV cortical neurons treated with TAT-spacer-GADD45 $\beta_{60-86}(5 \mu \mathrm{M}), 100 \mu \mathrm{M}$ NMDA, or the combination of the treatments for 5 (upper panel), 30 (middle panel) and $60 \mathrm{~min}$ (lower panel). Actin was used as loading control. Data are presented as mean \pm S.E.M. (two-way ANOVA, Tukey's post-hoc test, ${ }^{*} P<0.05$ CTR versus NMDA, ${ }^{* \star *} P<0.001$ CTR versus NMDA, ${ }^{\#} P<0.05$ NMDA versus NMDA + MKK71, ${ }^{\# \#} P<0.001$ NMDA versus NMDA + MKK71, $\left.n=6\right)$. (b) Western blotting and relative quantification of P-MKK4/MKK4 ratio in 12 DIV cortical neurons treated with TAT spacer-GADD45 $\beta_{60-86}$ peptide $(5 \mu \mathrm{M}), 100 \mu \mathrm{M}$ NMDA, or the combination of the treatments for 5 (upper panel), 30 (middle panel) and $60 \mathrm{~min}$ (lower panel). Actin was used as loading control. Data are presented as mean \pm S.E.M. (two-way ANOVA, interaction $40.05, n=6)$

treated with GADD45 $\beta$ - I peptide $(n=3)$ displayed a significant decrease in the infarct volume compared with control rats at $24 \mathrm{~h}(n=4)$ (Figures 7 and b). The total mean infarct volumes were quantified using the Neurolucida software (Microbrightfield, Williston, VT, USA) and Cavalieri's geometry on TTC-stained sections $24 \mathrm{~h}$ after thromboembolic occlusion of the MCA (Figures 7a and b). All animals showed an ipsilateral ischemic damage, that is, in the right lateral frontoparietal cortex (Figures $7 \mathrm{a}$ and b). Pre-ischemic injection of GADD $45 \beta$ - I reduced the infarcted volume by $50 \%$ (Figure 7c). The percentage of ischemic lesion on the whole brain volume was $9.47 \pm 1.96 \%$ in GADD $45 \beta-1-$ treated rats versus $18.88 \pm 4.38 \%$ in the control group $\left({ }^{* *} P<0.01\right)$ (Figure 7c). These data indicated the powerful neuroprotective effect of GADD $45 \beta-$ I against brain injury induced by thromboembolic ischemia in rats.

\section{Discussion}

JNK is a Janus-faced molecule, which may both protect and damage neurons, regulated by the two upstream activators, MKK4 and MKK7, which are not redundant, ${ }^{18,19}$ and respond differently to stress stimuli, ${ }^{8-10}$ representing a 'bottleneck' in its activation. 
b

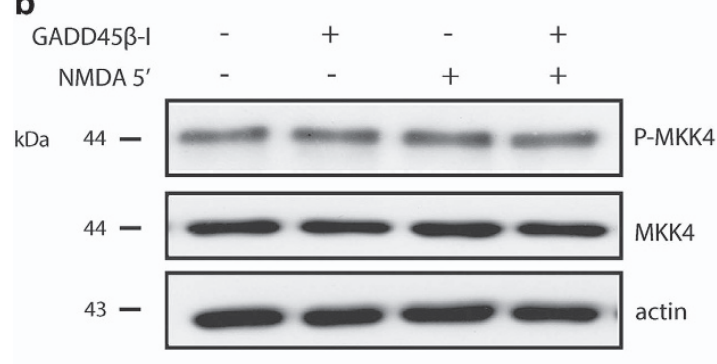

P-MKK4/MKK4 $5^{\circ}$

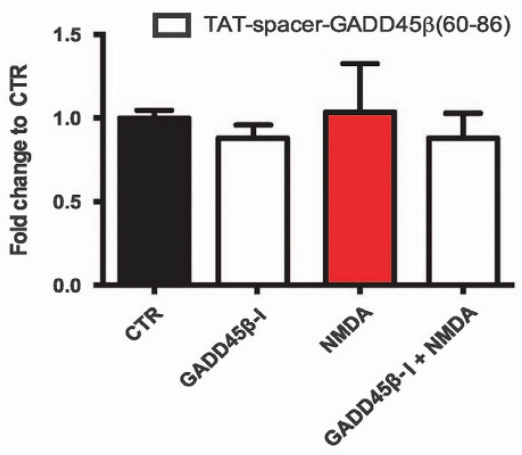

P-MKK4/MKK4 30'

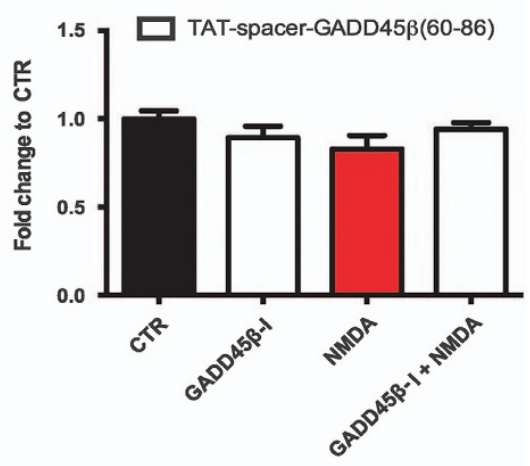

P-MKK4/MKK4 60'

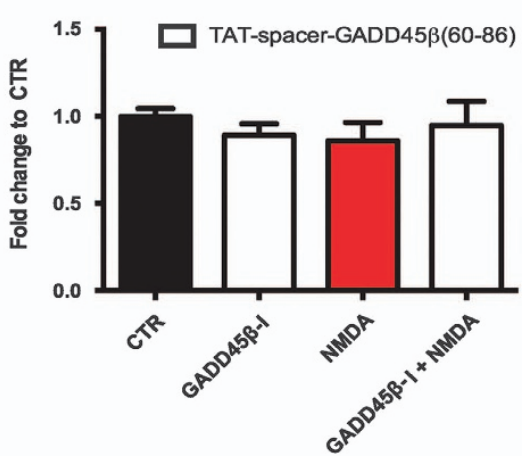

Figure 4 Continued

We found that MKK7, and not MKK4, mediates the activation of JNK signaling in excitotoxic neuronal death ${ }^{3}$ and cerebral ischemia. ${ }^{4}$ Here we show, for the first time, that MKK7-specific inhibition represents a good strategy to prevent excitotoxic neuronal death and overcome possible side effects occurring in response to JNK inhibition. ${ }^{13}$

We designed a new MKK7 inhibitor peptide by modeling the minimal region necessary for the binding and coupling it with the TAT peptide, to allow penetration of the blood-brain barrier and neuronal membrane. A spacer was introduced between the TAT and the GADD $45 \beta$ sequences previously discovered. ${ }^{9}$ This allowed to functionally separate the different domains of GADD $45 \beta-I$, guaranteeing the entry of the peptide into neurons (TAT sequence), and the ability to interact with MKK7 and inhibit its function (GADD45 $\beta$ sequence). Moreover, the spacer sequence helped in stabilizing the peptide and in increasing its solubility. The introduction of the spacer and the use of the longer sequence, which includes the seven negatively charged residues, increased the efficiency of the inhibitor peptide. In fact, in vitro, GADD45 $\beta$ - I (TAT-spacerGADD45 $\beta_{60-86}$ ) showed a more potent neuroprotective effect against excitotoxicity, if compared with the shorter TATGADD45 $\beta_{69-86}$ peptide. TAT-spacer-GADD45 $\beta_{60-86}$ peptide completely protected from OGD in vitro, confirming the key role of MKK7 also in this model. All together, the in vitro results obtained with the SPR and the mutated peptide (TATGADD $45 \beta_{69-86}$ CONTROL) demonstrate the selectivity of GADD45 $\beta$-I peptide for MKK7.

Finally, the peptide showed no toxicity by itself on neurons, suggesting its safety for in vivo treatments. To validate 
$24 \mathrm{~h}$

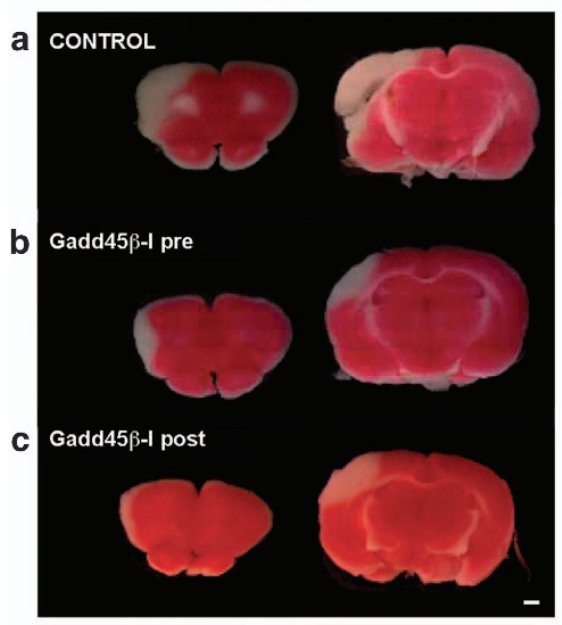

d

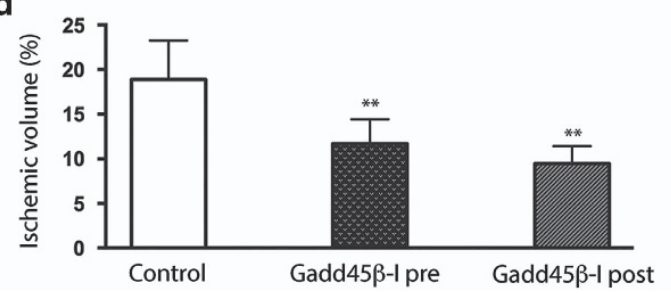

1 week

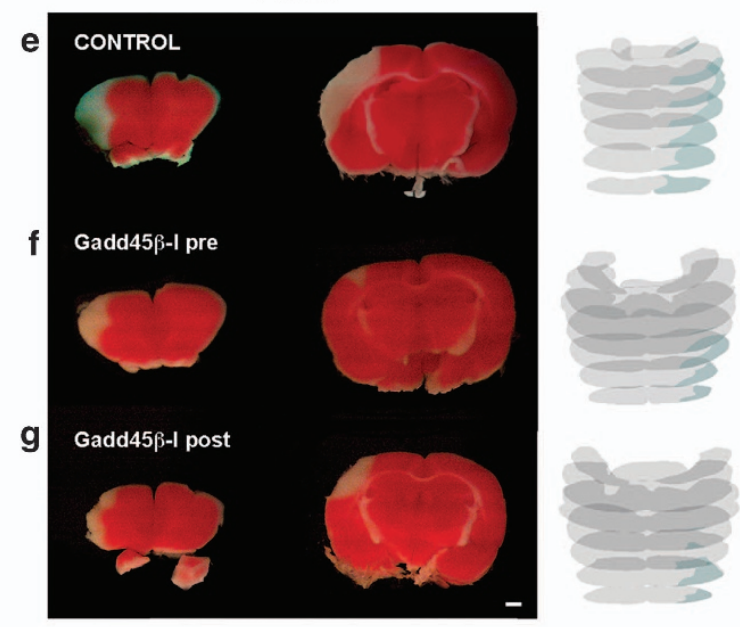

h

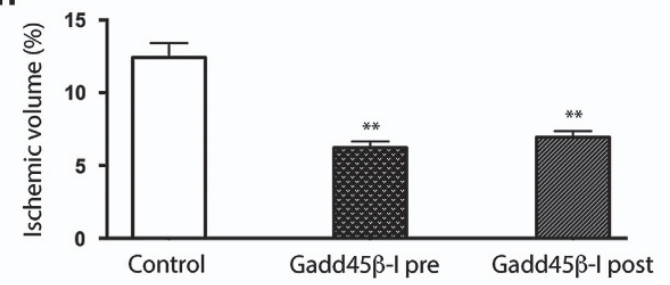

Figure 5 GADD45 $\beta$-I protects against MCAO. Rats were injected with (a) vehicle or with (b) GADD45 $\beta$-I (11 mg/kg) 30 min before lesion or with (c) GADD45 $\beta$-I (11 mg/kg) $6 \mathrm{~h}$ after lesion. All groups were killed $24 \mathrm{~h}$ after lesion. Brains were extracted and colored with TTC staining to reveal ischemic areas. Ischemic volume was measured for all the three experimental groups with NIH ImageJ analysis software. Images 4A-C are TTC-stained slices at different levels of a representative animal for each different groups (scale bar $1 \mathrm{~mm}$ ). In addition, we show a full reconstruction of the lesion size (blue shade on gray) obtained with contour analysis through Neurolucida software. (d) Percentage of ischemic volume for the two groups (GADD45 $\beta-130$ min before lesion $n=6$ and GADD45 $\beta-16 \mathrm{~h}$ after lesion $n=5$ ) of treated animals was compared with untreated animals $(n=6)$. Data represent mean \pm S.D.; one-way ANOVA, Dunnett's post-hoc test, ${ }^{\star \star} P<0,01$. Rats were injected with (e) vehicle 30 min before lesion or with (f) GADD45 $\beta$-I (11 mg/kg) $30 \mathrm{~min}$ before lesion, or with $(\mathrm{g})$ GADD $45 \beta-\mathrm{I}(11 \mathrm{mg} / \mathrm{kg}) 6 \mathrm{~h}$ after lesion. All groups were killed $24 \mathrm{~h}$ after lesion. Brains were extracted and colored with TTC staining to reveal ischemic areas. Ischemic volume was measured for all the three experimental groups with NIH ImageJ analysis software. Images 4A-C are TTC-stained slices at different levels of a representative animal for each different groups (scale bar $=1 \mathrm{~mm}$ ). In addition, we show a full reconstruction of the lesion size (blue shade on gray) obtained with contour analysis through Neurolucida software. (h) Percentage of ischemic volume for the two groups (GADD45 $\beta$-I 30 min before lesion $n=5$ and GADD45 $\beta$ - 6 h after lesion $n=5$ ) of treated animals was compared with untreated animals $(n=5)$. Data represent mean \pm S.D.; one-way ANOVA, Dunnett's post-hoc test, ${ }^{* *} P<0.01$

GADD45 $\beta$-I for clinical applications, we tested it in two in vivo models of cerebral ischemia: the MCAo and the thromboembolic ischemia. Administration of the peptide before the ischemic insult prevented neuronal death, reducing the infarct volume of $43 \% 24 \mathrm{~h}$ after lesion. The neuroprotective effect was maintained also when the peptide was administered $6 \mathrm{~h}$ after ischemia, extending its clinical window. Currently, the utilization of tissue plasminogen activator, the only pharmacological treatment approved for ischemic stroke, ${ }^{20}$ is restricted by the narrow therapeutic window (3-4.5 h) and the limited efficacy, as only a sub-optimal dose $(0.9 \mathrm{mg} / \mathrm{kg})$ can be administered, owing to the risk of iatrogenic intracranial hemorrhage ${ }^{21-23}$, limiting treatment to an estimated $2-5 \%$ of ischemic stroke patients in the United States. ${ }^{24}$ Importantly, also in vivo GADD45 $\beta$ - I inhibited MKK7 activity and its inhibition is in agreement with the protection obtained on infarcted volumes at $24 \mathrm{~h}$ as well as at 1 week after lesion. Our protection in vivo lasts at least 1 week, thus suggesting that the effect of treatment is permanent and does not consist in a mere delay in neuronal death. The time course of phosphorylation of MKK7, that is, of its activation, is compatible with the administration time of GADD $45 \beta-\mathrm{I}$, that is, $3-6 \mathrm{~h}$ after the lesion. GADD $45 \beta$ - I revealed efficient in reducing the infarct size in both the in vivo models tested. Even though the thromboembolic model resembles the most adherent to human stroke, the MCAo is by and large the most commonly used for testing new drugs against excitotoxicity.

We are aware that notwithstanding the significant results obtained in preclinical studies by blocking specific molecular pathways, their clinical application remains poor ${ }^{25,26}$ and no approved therapy exists for stroke other than thrombolysis. This failure in translation from bench to bedside has led to the recommendations on the stroke therapy academic industry roundtable (STAIR), ${ }^{27}$ even though clinical trials fulfilling the STAIR criteria for EPO or G-CSTS did not confirm preclinical experimentation as well. ${ }^{28}$ The reasons for this failure are multifarious, ranging from the plurality of mechanisms of cell death, ${ }^{29}$ the side effects of activity blockade to prevent excitotoxicity and the general conditions of the patient due to comorbidities.

A strategy would be blocking the excitotoxic cascade at the level of the activation of NMDA receptors by glutamate release inhibition, NMDAR antagonists, $\mathrm{Na}^{+}$- or $\mathrm{Ca}^{++}$channel blockers. All of these had significant effects on neuronal death, but 
a

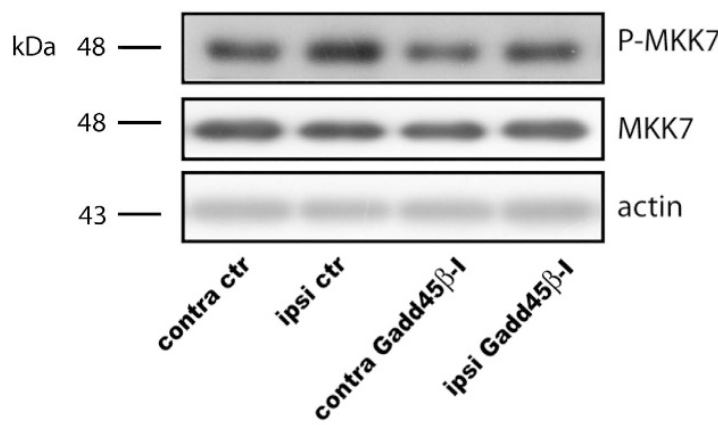

b

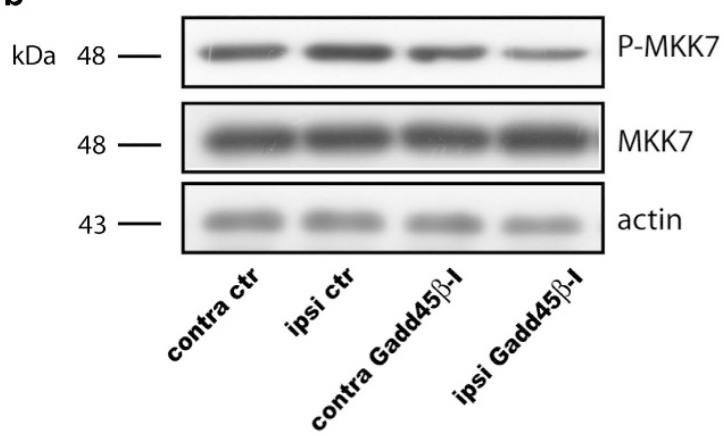

C

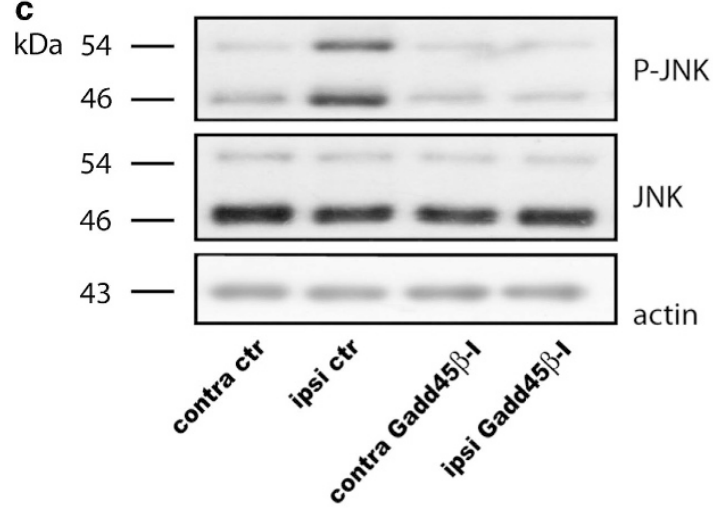

d

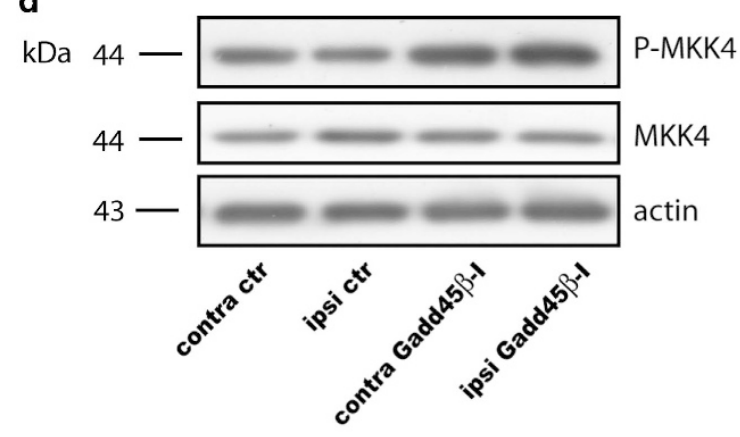

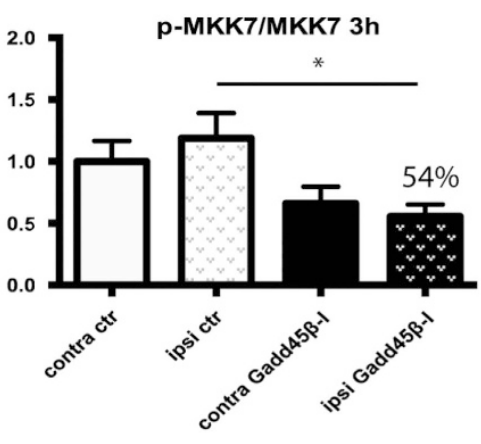
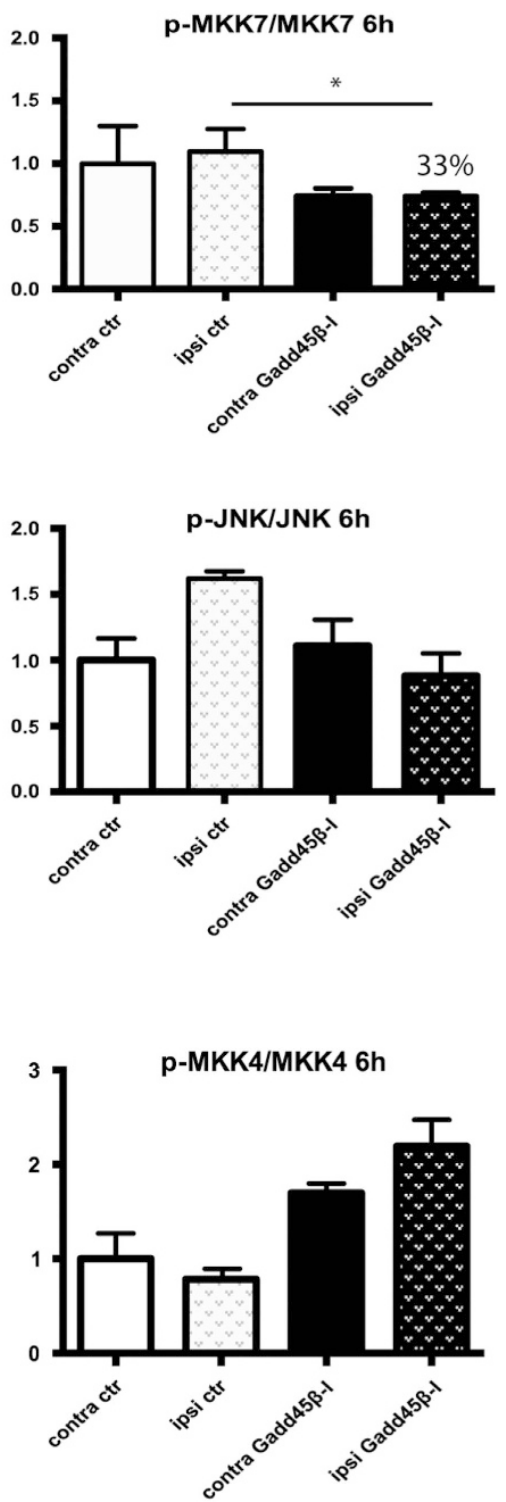

Figure 6 GADD45 $\beta$-I inhibits MKK7 activation $3 \mathrm{~h}$ post lesion. Western blotting and relative quantification of contralateral and ipsilateral brain samples. Animals were pre-treated with GADD45 $\beta$-I (11 mg/kg 30 min before MCAO) and killed 3 and $6 \mathrm{~h}$ after lesion. (a) Western blotting and relative quantification of P-MKK7/MKK7 ratio $3 \mathrm{~h}$ after lesion. Actin was used as loading control. Data are presented as mean \pm S.E.M. (two-way ANOVA, Tukey's post-hoc test $\left.{ }^{*} P<0.05, n=3\right)(\mathbf{b})$ Western blotting and relative quantification of P-MKK7/MKK7 $6 \mathrm{~h}$ after lesion. Actin was used as loading control. Data are presented as mean \pm S.E.M. (two-way ANOVA, Tukey's post-hoc test ${ }^{*} P<0.05$, $n=3$ ) (c) Western blotting and relative quantification of P-JNK/JNK ratio $6 \mathrm{~h}$ after lesion. Actin was used as loading control. Data are presented as mean \pm S.E.M. (two-way ANOVA, interaction $>0.05, n=3$ ) (d) Western blotting and relative quantification of P-MKK4/MKK4. Actin was used as loading control. Data are presented as mean \pm S.E.M. (two-way ANOVA, interaction $>0.05, n=3$ ) 

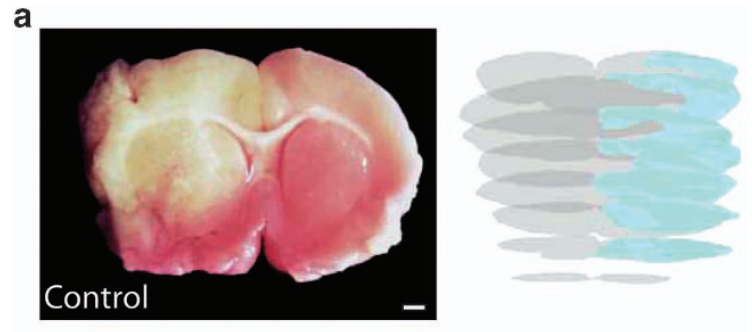

b
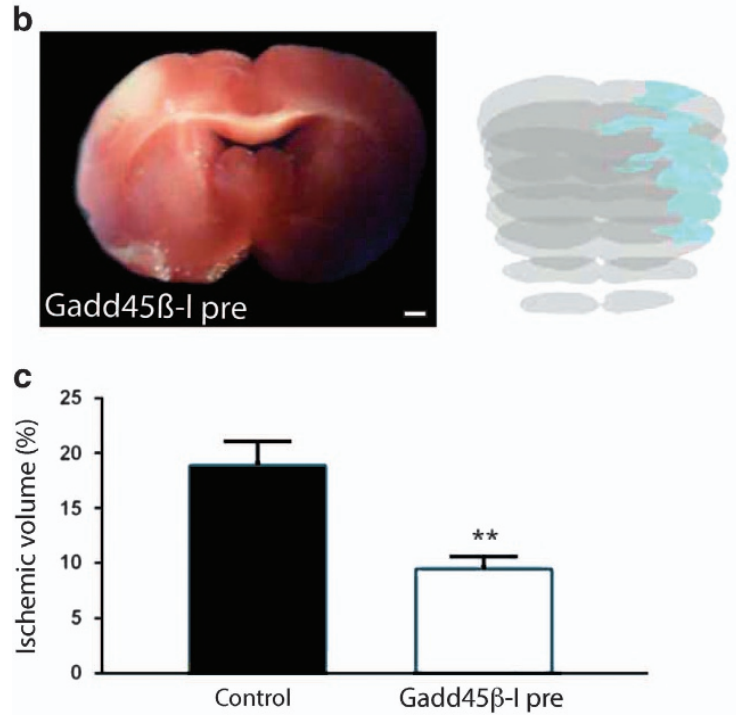

Figure 7 GADD45 $\beta$-I peptide protects against thromboembolic ischemia. Rats were pre-treated with vehicle (a) or GADD $45 \beta$-I ( $11 \mathrm{mg} / \mathrm{kg}, 30 \mathrm{~min}$ before lesion) (b) and killed $24 \mathrm{~h}$ post lesion. Brains from control (a) and GADD $45 \beta$ - l-treated (b) rats were extracted and colored with TTC staining to show ischemic region. Images 6A-B are TTC-stained representative slices of the two experimental groups (scale bar $=1 \mathrm{~mm}$ ). In addition, we show a full reconstruction of the lesion size (blue shade on gray) obtained with contour analysis through Neurolucida software. (c) Percentage of ischemic volume was measured with Neurolucida software and Cavalieri's geometry Treated animals were compared with untreated animals. Data represent mean \pm S.D. (Student's $t$-test ${ }^{* *} P<0.05, n=3$ )

showed remarkable neurological and non-neurological side effects in clinical trials. ${ }^{30}$ Furthermore, a certain degree of NMDAR activation may be neuroprotective, ${ }^{31}$ eventually through the activation of the Akt pathway. ${ }^{32}$ An opposed effect has been shown for phosphatase and tensin homolog deleted on chromosome 10 (PTEN) pathway, which mediates NMDAR-induced death signaling. Its inhibition by a TAT-k13 peptide is neuroprotective against cerebral ischemia. ${ }^{33}$ No cross-links between the PTEN and the JNK pathways have been described thus far. The major neuroprotective effects both in experimental and in clinical conditions have been obtained with peptides targeting the PSD95-nNOS interaction (NR2B9c) in rodents, ${ }^{34}$ primates $^{35}$ and, finally, in clinical trial. $^{35,36}$ In fact, the binding of PSD95 to the NMDAR and nNOS brings nNOS into close proximity with the NMDAR channel pore and with the $\mathrm{Ca}^{++}$that fluxes through the NMDAR, thus activating the enzyme. ${ }^{37,38}$

Recently, as an alternative strategy, we found that M5, a mutant of native urokinase plasminogen activator (prouPA), can reduce infarct size with a reduced risk of bleeding. ${ }^{39}$
In addition, preconditioning stimuli reduce the effects of cerebral ischemia, ${ }^{40}$ thus suggesting the administration of gaseous carbon monoxide or carbon monoxide donors (CORMs). ${ }^{41}$ Cell-based therapy has also been proposed to modulate neuroinflammation, replace dying neurons and stimulate brain repair by enhancing neurogenesis and angiogenesis, but it is far from clinical therapy. ${ }^{42}$

Our inhibitor may represent an important tool to specifically prevent the development of excitotoxicity in neurons, in the absence of side effects and with a very interesting therapeutic window. It might be associated to drugs acting on different pathways of death as well as to increase their efficacy. For example, blocking excitotoxicity could extend the therapeutic window for thrombolysis as well.

The in vivo results support its high therapeutic potential against cerebral ischemia. For the first time, specific inhibition of MKK7 was sufficient to prevent excitotoxicity in vitro as well as cerebral ischemia in two different in vivo models. ${ }^{2,4,39}$ This confirms that excitotoxicity/cerebral ischemia leads to activation of MKK7/JNK pathway, without activating MKK4/JNK. Importantly, GADD45 $\beta$-I still prevented neuronal death after 1 week from the lesion, proving that the peptide really blocks neuronal death program after lesion and not just postpone it in time.

Compared with D-JNKI1 (specific inhibitor of all JNKs isoforms), ${ }^{2}$ GADD $45 \beta$-I reduced the infarct volume by $45 \%$, whereas D-JNKI1 reduced by $93 \%$ at the same temporal window (6h); both peptides block neuronal death. The advantage of inhibiting MKK7 (GADD45 $\beta$-I), instead of JNK (D-JNKI1), lies in the fact that the JNK physiological role, controlled by MKK $4,{ }^{43}$ is preserved with GADD $45 \beta$-I treatment

\section{Conclusions}

GADD $45 \beta-1$ is markedly neuroprotective against in-vitro excitotoxicity and OGD in cortical neurons, and more importantly against two experimental stroke models. GADD45 $\beta$ - I specifically decreases MKK7 phosphorylation/ activation and reduces the infarct volume by $45-50 \%$ at $24 \mathrm{~h}$ post lesion, when injected $6 \mathrm{~h}$ post ischemia. GADD $45 \beta-\mathrm{I}$ (injected $6 \mathrm{~h}$ post ischemia) reduces infarct volume by $49 \%$ at 1 week after lesion, proving that GADD $45 \beta-1$ is able to inhibit and not just postpone neuronal death after ischemia. We therefore conclude that this agent offers great promise for developing therapies for cerebral ischemia.

\section{Materials and Methods}

Modeling and docking design. Up to now the three-dimensional structure of GADD45 $\beta$ is not available and for this reason it has been obtained through homology modeling, using as a template the structure of the GADD45 $\alpha$ (Protein Data Bank (PDB) ID: $2 \mathrm{KGA})^{44}$ sharing $60 \%$ of identity with our sequence of interest. ${ }^{14}$ After the modeling, the structure obtained has been minimized for 1000 step using the Steepest Descent algorithm. ${ }^{45}$ The atomic coordinates of MKK 7 have been solved and are available in the PDB (PDB ID: 2DYL), but the residues composing the three loops, 143-148, 282-296 and 307-314, are lacking. These regions have been modeled using the loops databank of the Swiss PDB viewer Version 4.1 program. ${ }^{46}$

In order to predict the GADD45 $\beta$-MKK7 complex, 100 runs of docking using the HADDOCK web server, ${ }^{47}$ in particular suitable for the protein-protein docking, have been carried out. The results of the docking runs have been clustered based on the RMSD criterion, using a $4.5-\AA$ cutoff. The best GADD $45 \beta$-MKK7 complex has been chosen by considering the HADDOCK score, which is calculated according to the 
weighted sum of various energy terms: van der Waals, electrostatic, restraints, diffusion anisotropy, dihedral angle restraints, symmetry restraints, buried surface area, binding and desolvation energies (see the HADDOCK manual for further information ${ }^{47}$ ). Docking simulations of the GADD45 $\beta$-MKK7 have generated 10 families, where the cluster with the best HADDOCK score contains $60 \%$ of total complexes generated after the 100 runs. The best structure of this cluster has been selected for the study of the interaction between GADD45 $\beta$ and MKK7 in order to design the peptides.

Peptide synthesis. The synthetic peptides TAT-GADD45 $\beta_{69-86}$ (aminoacidic sequence: $5^{\prime}$-IALQIHFTLIQSFCCDNDGRKKRRQRRR-NH ${ }_{2}-3^{\prime}$ ) and TAT-spacerGADD45 $\beta_{60-86}$ (aminoacidic sequence: $5^{\prime}$-DEEEEDDIALQIHFTLIQSFCCDNDAGA GAAAGRKKRRQRRR- $\mathrm{NH}_{2}-3^{\prime}$ ) were prepared by solid-phase peptide synthesis method using a multiple peptide synthesizer (Syroll, MultiSynTech GmbH, Witten, Germany) on 4-(2',4'-dimethoxyphenyl-Fmoc-aminomethyl)-phenoxyacetamido norleucyl-MBHA resin (100-200 mesh) (Novabiochem). The fluoren-9ylmethoxycarbonyl $(F m o c)$ strategy ${ }^{48}$ was used throughout the peptide chain assembly, using O-(7-Azabenzotriazol-1-yl)- $N, N, N, N$-tetramethyluronium hexafluorophosphate as the coupling reagent. ${ }^{49}$ The side-chain-protected amino acid building blocks used were as follows: $N$ - $\alpha$-Fmoc- $\mathrm{N} \omega$-(2,2,4,6,7-pentamethyldihydrobenzofuran-5-sulfonyl)-L-arginine, $N$ - $\alpha$-Fmoc- $\gamma$-tert-butyl-L-glutamic acid, $N$ - $\alpha$-Fmoc- $\beta$-tertbutyl-L-aspartic acid, $N$ - $\alpha$-Fmoc-O-tert-butyl-L-serine, $N \alpha$-Fmoc-O-tert-butyl-L-threonine, $\quad N$ - $\alpha$-Fmoc- $N \varepsilon$-(tert-butyloxycarbonyl)-L-lysine, $\quad N$ - $\alpha$-Fmoc- $N$ (im)-trityl-L-histidine, $N$ - $\alpha$-Fmoc- $N-\gamma$-trityl-L-glutamine, $N$ - $\alpha$-Fmoc-S-trityl-cystine and $N-\alpha-F m o c-N$ $\beta$-trityl-L-asparagine. Cleavage of the peptides was performed by reacting the peptidyl resins with a mixture containing TFA/ethanedithiol/phenol $5 \%$ for $2.5-3 \mathrm{~h}$. Crude peptides were purified by a preparative reverse-phase HPLC. Molecular masses of the peptides were confirmed by mass spectroscopy on a MALDI TOF-TOF mass spectrometer (model 4800, AB Sciex, Framingham, MA, USA). The purity of the peptides was in the range $90-95 \%$ as evaluated by analytical reverse-phase HPLC.

SPR analyses. Binding studies were performed on a ProteOn XPR36 Protein Interaction Array system (Bio-Rad Laboratories, Hercules, CA, USA). Detection of GADD45 $\beta_{69-86}$ interaction with MKK7 was performed by immobilizing $\sim 5000$ resonance units (RUs) of human recombinant full-length MKK7 (residues M1-R419, as in NCBI/Protein entry NP_660186.1; ProQinase GmbH, Freiburg, Germany) on the surface of a sensor chip (GL-C chip, Bio-Rad) by amine-coupling chemistry. GADD45 $\beta_{69-86}$ molecules were then perfused over the chip for $150 \mathrm{~s}$ to allow association, followed by $500 \mathrm{~s}$ buffer (PBST) wash to monitor dissociation. Signals were normalized to control channels containing $~ 5000 \mathrm{RUs}$ of bovine serum albumin or no proteins. The resulting sensorgrams were fitted to a heterogenous ligand binding model using the ProteOn analysis software, to obtain the corresponding association and dissociation rate constants $\left(k_{\text {on }}\right.$ and $k_{\text {off }}$ respectively) and the equilibrium dissociation constant $\left(K_{\mathrm{D}}\right)$.

Cortical neuronal culture. Cortical pieces were dissected from the brains of 2-day-old rat pups, incubated with $200 \mathrm{U}$ of papain for $30 \mathrm{~min}$ at $34^{\circ} \mathrm{C}$ and, after trypsin inhibitor (Sigma Aldrich, St Louis, MO, USA) treatment (1\%, $45 \mathrm{~min}$ at room temperature), were mechanically dissociated. Neurons were then plated at densities of $\sim 5 \times 10^{5}$ cells/plate on 3.5-mm tissue culture dishes (BD, San Jose, CA, USA) and $5 \times 10^{4}$ cells/plate on 95-well culture plates (SPL Life Sciences, Pocheon, South Korea) all pre-coated with $10 \mu \mathrm{g} / \mathrm{ml}$ poly-D-lysine (Sigma Aldrich) and $2 \mu \mathrm{g} / \mathrm{ml}$ laminine (Life Technologies, Gaithersburg, MD, USA). The plating medium consisted of Neurobasal Medium (Life Technologies) supplemented with 2\% B27 (Life Technologies), $50 \mathrm{mM}$ glutamine (Life Technologies) and $1000 \mathrm{U} / \mathrm{ml}$ penicillin/streptomycin (Life Technologies). Experiments were performed after 1113 days in culture, at which time the neurons had elaborate axonal and dendritic arbors, and had formed many synapses. GADD $45 \beta$ inhibitors were added to the dishes at the desired concentrations, 30 min before NMDA treatment $(100 \mu \mathrm{M}$, Abcam, Cambridge, UK).

All experimental procedures on animals were done in accordance with the European Communities Council Directive of 24 November 1986 (86/609/EEC) and all efforts were made to minimize animal suffering.

Oxygen-glucose deprivation. OGD was performed on cortical neurons maintained in an Hypoxia Incubator Chamber (StemCell Technologies, Vancouver, $\mathrm{BC}$, Canada) for $12 \mathrm{~h}$; during the first $4 \mathrm{~min}$, oxygen in the chamber was replaced by a mixture of $95 \% \mathrm{~N}_{2} 5 \% \mathrm{CO}_{2}$; glucose deprivation was realized by substituting culture medium with glucose-free Neurobasal Medium (Life Technologies).

Peptides administration. All treated rats underwent ICV administration $(-1 \mathrm{AP},+2 \mathrm{ML},-3 \mathrm{DV}), 30 \mathrm{~min}$ before or $6 \mathrm{~h}$ post lesion, of GADD45 $\beta$-I $(11 \mu \mathrm{g} / \mu \mathrm{l})$ ipsilaterally to the lesion. Animals were anesthetized with isoflurane (4\% during induction, then maintained with 1.5\%) in a mixture of $30: 70 \mathrm{O}_{2} / \mathrm{N}_{2} \mathrm{O}$ and placed in a Stereotaxic Apparatus (Stoelting, 51600, Wood Dale, IL, USA). Injection ( $2 \mu$ l volume) was made with a graduate glass pipette through an osmotic pump to minimize side effects.

LDH cytotoxicity assay. Neuroprotection was evaluated by an LDH assay. $\mathrm{LDH}$ released into the bathing medium 5-24 $\mathrm{h}$ after NMDA was measured using the Cytotox 96 non-radioactive cytotoxicity assay kit (Promega, Fitchburg, WI, USA), according to the manufacturer's indications.

Western blot analysis. Proteins were separated by $10 \%$ SDS-PAGE and transferred to a PVDF membrane. Incubation with primary antibodies was overnight at $4{ }^{\circ} \mathrm{C}$ using the following: $1: 1000$ anti-MKK7 (4172, Cell Signaling Technology, Beverly, MA, USA), 1:1000 anti-P-MKK7 (4171, Cell Signaling Technology), 1:1000 anti-MKK4 (07-194 Upstate, Charlottesville, VA, USA), 1: 1000 anti-PMKK4 (9151, Cell Signaling Technology), 1: 1000 anti-JNK (9252S, Cell Signaling Technology) and 1:1000 anti-P-JNK (9252S, Cell Signaling Technology). All P-antibodies, P-MKK7, P-MKK4 and P-JNK, are specific and recognize only the phosphorylated form of these proteins (they do not recognize cortical neuronal extracts dephosphorylated with alkaline phosphatase overnight). In a single experiment, a very large number of neurons were analyzed, providing very consistent results, and the blots were all normalized with respect to actin $(1: 10000$ anti-actin, 1501 Millipore, Billerica, MA, USA). Blots were developed using horseradish peroxidase-conjugated secondary antibodies (goat anti mouse IgGHRP and goat anti rabbit lgG-HRP, both from Santa-Cruz Biotechnology, Santa Cruz, CA, USA) and the ECL chemiluminescence system (Promega).

Quantification. The quantification of western blottings was performed using ImageQuant TL software (Amersham Biosciences, Amersham, UK) and was based on at least three independent experiments.

\section{Ischemic models}

Ethical statement. Male adult Sprague-Dawley rats (Harlan, Lesmo, Italy) weighing $270-350 \mathrm{~g}$ were used in this study. All animal experimental procedures were approved and carried out in accordance to the European Community Council Directive 86/609/EEC (24 November 1986), Italian Ministry of Health and University of Turin institutional guidelines on animal welfare (law 116/92 on Care and Protection of living animals undergoing experimental or other scientific procedures; authorization number 17/2010-B, 30 June 2010) and ad-hoc Ethical Committee of the University of Turin. Free access to food and water was maintained and all efforts were made to minimize suffering and limit the number of animals used.

Part I. Ischemia reperfusion $(n=43)$. The MCA was cauterized by the method described by Renolleau et al. ${ }^{50}$ Rats were anesthetized with isoflurane (4\% during induction, then maintained with $1.5 \%$ ), in a mixture of $30: 70 \mathrm{O}_{2} / \mathrm{N}_{2} \mathrm{O}$ delivered with a face mask throughout the surgery duration. Briefly, under an operating microscope (Nikon, Sesto Fiorentino, Italy), a midline incision of the head was performed, the temporal muscle dissected and the temporal bone exposed; a burr hole was drilled very close to the zygomatic arch and the left MCA was identified. The MCA main branch was then electrocoagulated close to its origin at the junction with the olfactory branch. Thereafter, a median incision was made in the neck to expose the left common carotid artery (CCA), which was transiently occluded by a clip in order to reduce infarct size variability due to anastomoses in the MCA territory. After $90 \mathrm{~min}$, the clip was removed. Successful occlusion was confirmed by progressive whitening of the cortex. Animals were initially killed $24 \mathrm{~h}$ post lesion. To further confirm the neuroprotective effect of our MKK7 inhibitor at a chronic condition, the same experimental groups were replicated but the animals were killed 7 days after lesion. In another set of experiments, control $(n=3)$ and treated $(n=3)$ rats were killed $6 \mathrm{~h}$ post surgery, to analyze the $\mathrm{p}-\mathrm{JNK} / \mathrm{JNK}$ ratio and MKK7/4 activation by western blotting.

Part II. Thromboembolic ischemia $(n=7)$. Ischemia was induced by injection of autologous blood clots in suspension into the internal carotid artery (ICA), as described by Busch et al. ${ }^{51}$ In order to prepare blood clots for embolism, femoral 
arterial blood from a donor rat was collected into a 20-cm long PE-50 catheter and retained for $2 \mathrm{~h}$ at room temperature, and subsequently at $4{ }^{\circ} \mathrm{C}$ for $22 \mathrm{~h}$ to allow clot formation to go to completion. Clots were pushed out of the catheter with a salinefilled syringe, rinsed several times in a Petri dish containing phosphate-buffered solution (PBS, pH 7.4), in order to remove blood cells and obtain a white clot, then inspected under the microscope to select fibrin-rich fragments. These fragments were cut into 2-mm-long pieces and transferred into a solution containing $1 \mathrm{mg} / \mathrm{ml}$ albumin in PBS, to allow clot retraction. Approximately $2 \mathrm{~h}$ later, 20 fibrin-rich fragments were drawn up in the albumin solution in 1-m-long PE50 catheter, taking care to maintain $\sim 3 \mathrm{~cm}$ distance between clots in order to keep them apart, and all embolized into MCA origin.

Surgical procedures: Rats were anesthetized with isoflurane (4\% during induction, then maintained with $1.75 \%$ ), in a mixture of $30: 70 \mathrm{O}_{2} / \mathrm{N}_{2} \mathrm{O}$ delivered with a face mask throughout the surgery duration. After a longitudinal incision of $2 \mathrm{~cm}$ in length in the midline of the ventral cervical skin, left CCA, ICA and external carotid artery (ECA) were carefully dissected and exposed, avoiding any damage to the adjacent vagus nerve. Inferior thyroid and occipital arteries, branching from the ECA, were visualized and cauterized; the distal portion of ECA was ligated and cut along with the terminal lingual and maxillary artery branches, and the carotid bifurcation identified. ICA was dissected cranially up to the origin of pterygopalatin branch, which was ligated using a 6/0 suture. A 5-0 silk suture was loosely tied around the origin of ECA, and then the CCA and ICA were temporarily clamped using microvascular clips. A PE-50 catheter, containing blood clot suspension, with a modified 0.3-mm outer diameter, was introduced into the ECA stump through a small puncture and advanced $1-2 \mathrm{~mm}$ beyond carotid bifurcation; the $5 / 0$ suture was tightened around the catheter to prevent backflow bleeding. The clip around ICA was removed and clots injected within $30 \mathrm{~s}$, whereas CCA was still occluded. At the end of injection, the catheter was withdrawn, the ECA stump was ligated and the CCA clip removed, so that blood pressure could push clots cranially. The wound was then closed; the rat was allowed to completely recover from anesthesia and returned to its cage. The surgery was complete in $\sim 30 \mathrm{~min}$.

Functional neuroscore: Functional outcome was tested at 2 and $24 \mathrm{~h}$ by observers blinded to the pharmacological regimen. A 5-point scale described by Longa et al. ${ }^{52}$ was used (grade 0: no neurological deficit; grade 1: failure to fully extend left forepaw; grade 2: contralateral circling; grade 3: contralateral falling; grade 4: absence of spontaneous movement or unconsciousness). The neuroscore was also used to further confirm that successful thrombotic occlusion had been achieved, as the existence of initial neurological deficit is a reliable predictor for successful occlusion of the MCA, ${ }^{.3,54}$ only animals grade 1 or higher at $2 \mathrm{~h}$ were included in the study. Exclusion of animals took place before assignment into the various treatment groups.

Functional neuroscore was also assessed 7 days after surgery in animals lesioned with MCAo.

Determination of infarct volumes: At $24 \mathrm{~h}$, the animals were euthanized, brains were removed, cooled on ice and then coronally cut into 2-mm-thick sections using a tissue slicer, starting from $2 \mathrm{~mm}$ caudal to the frontal tip. Sections were immediately stained with $2 \%$ TTC (Sigma) at $37^{\circ} \mathrm{C}$ for $10 \mathrm{~min}$, then fixed in $4 \%$ phosphate-buffered formalin as previously described. ${ }^{55}$ Each slice was examined for subarachnoid hemorrhage. Slices were scanned with a Coolpix camera (Nikon); infarct volume and brain edema were measured using NIH ImageJ analysis software (available at http://rsb.info.nih.gov/ij). Ischemic volumes were calculated as the sum of infarcted area (in $\mathrm{mm}^{2}$ ) multiplied by slice thickness $(\sim 2 \mathrm{~mm}$ ). Edema volumes were calculated by subtracting the contralateral hemisphere volume from the ischemic hemisphere volume; for edema correction, the equation ischemic volume $\times$ contralateral hemisphere/ipsilateral hemisphere volume was used, as previously described. ${ }^{56}$ Seven 2 -mm-thick slices were measured for each brain.

Statistical analysis. Statistical analysis was done using Stat-View software. Data were calculated as mean \pm S.E. Differences between groups were compared using Student's t-test or one-way ANOVA and two-way ANOVA, followed by Dunnett's or Tukey's test. $P$-values $<0.05$ were considered significant.

\section{Conflict of Interest}

The authors declare no conflict of interest.
Acknowledgements. EB was supported by a Young Investigator Award (GR-2010-2312769) from the Italian Ministry of Health.

1. Lipton SA. Paradigm shift in neuroprotection by NMDA receptor blockade: memantine and beyond. Nat Rev Drug Discov 2006; 5: 160-170.

2. Borsello T, Clarke PG, Hirt L, Vercelli A, Repici M, Schorderet DF et al. A peptide inhibitor of c-Jun N-terminal kinase protects against excitotoxicity and cerebral ischemia. Nat Med 2003; 9: $1180-1186$.

3. Centeno C, Repici M, Chatton JY, Riederer BM, Bonny C, Nicod P et al. Role of the JNK pathway in NMDA-mediated excitotoxicity of cortical neurons. Cell Death Differ 2007; 14: 240-253.

4. Repici M, Centeno C, Tomasi S, Forloni G, Bonny C, Vercelli A et al. Time-course of C-Jun $\mathrm{N}$-terminal kinase activation after cerebral ischemia and effect of D-JNKI1 on C-Jun and caspase-3 activation2007 Neuroscience 150: 40-49.

5. Repici M, Mare L, Colombo A, Ploia C, Sclip A, Bonny C et al. C-Jun N-terminal kinase binding domain-dependent phosphorylation of mitogen-activated protein kinase kinase 4 and mitogen-activated protein kinase kinase 7 and balancing cross-talk between c-Jun $\mathrm{N}$-terminal kinase and extracellular signal-regulated kinase pathways in cortical neurons. Neuroscience 2009; 159: 94-103.

6. Davis RJ. Signal transduction by the JNK group of MAP kinases. Cell 2000; 103: 239-252.

7. Matsuoka M, Igisu H, Nakagawa K, Katada T, Nishina H. Requirement of MKK4 and MKK7 for $\mathrm{CdCl} 2$ - or $\mathrm{HgCl} 2$-induced activation of $\mathrm{c}$-Jun $\mathrm{NH} 2$-terminal kinase in mouse embryonic stem cells. Toxicol Lett 2004; 152: 175-181.

8. Harper SJ, LoGrasso P. Signalling for survival and death in neurones: the role of stressactivated kinases, JNK and p38. Cell Signal 2001; 13: 299-310.

9. Papa S, Zazzeroni F, Bubici C, Jayawardena S, Alvarez K, Matsuda S et al. Gadd45 beta mediates the NF-kappa B suppression of JNK signalling by targeting MKK7/JNKK2. Nat Cell Biol 2004; 6: 146-153.

10. Zhou G, Golden T, Aragon IV, Honkanen RE. Ser/Thr protein phosphatase 5 inactivates hypoxia-induced activation of an apoptosis signal-regulating kinase 1/MKK-4/JNK signaling cascade. J Biol Chem 2004; 279: 46595-46605.

11. Borsello $T$, Croquelois K, Hornung JP, Clarke PG. N-methyl-d-aspartate-triggered neuronal death in organotypic hippocampal cultures is endocytic, autophagic and mediated by the c-Jun N-terminal kinase pathway. Eur J Neurosci 2003; 18: 473-485.

12. Hirt L, Badaut J, Thevenet J, Granziera C, Regli L, Maurer F et al. D-JNKI1, a cell-penetrating C-Jun-N-terminal kinase inhibitor, protects against cell death in severe cerebral ischemia. Stroke 2004; 35: 1738-1743.

13. Davies C, Tournier C. Exploring the function of the JNK (c-Jun N-terminal kinase) signalling pathway in physiological and pathological processes to design novel therapeutic strategies. Biochem Soc Trans 2012; 40: 85-89.

14. Tornatore L, Marasco D, Dathan N, Vitale RM, Benedetti E, Papa S et al. Gadd45 beta forms a homodimeric complex that binds tightly to MKK7. J Mol Biol 2008; 378: 97-111.

15. Papa S, Monti SM, Vitale RM, Bubici C, Jayawardena S, Alvarez $\mathrm{K}$ et al. Insights into the structural basis of the GADD45beta-mediated inactivation of the JNK kinase, MKK7/JNKK2. J Biol Chem 2007; 282: 19029-19041.

16. Tian J, Locker J. Gadd45 in the liver: signal transduction and transcriptional mechanisms. Adv Exp Med Biol 2013; 793: 69-80.

17. Borsello T, Bonny C. Use of cell-permeable peptides to prevent neuronal degeneration. Trends Mol Med 2004; 10: 239-244.

18. Yamasaki T, Kawasaki H, Arakawa S, Shimizu K, Shimizu S, Reiner $O$ et al. Stress-activated protein kinase MKK7 regulates axon elongation in the developing cerebral cortex. J Neurosci 2011; 31: 16872-16883.

19. Wang X, Nadarajah B, Robinson AC, McColl BW, Jin JW, Dajas-Bailador F et al. Targeted deletion of the mitogen-activated protein kinase kinase 4 gene in the nervous system causes severe brain developmental defects and premature death. Mol Cell Biol 2007; 27: 7935-7946.

20. Tissue plasminogen activator for acute ischemic stroke. The National Institute of Neurological Disorders and Stroke rt-PA Stroke Study Group. N Engl J Med 1995; 333: $1581-1587$.

21. Cronin CA. Intravenous tissue plasminogen activator for stroke: a review of the ECASS III results in relation to prior clinical trials. J Emerg Med 2010; 38: 99-105.

22. Wang W, Li M, Chen $Q$, Wang J. Hemorrhagic transformation after tissue plasminogen activator reperfusion therapy for ischemic stroke: mechanisms, models, and biomarkers. $\mathrm{Mol}$ Neurobiol 2014.

23. Wardlaw JM, Sandercock PA, Berge E. Thrombolytic therapy with recombinant tissue plasminogen activator for acute ischemic stroke: where do we go from here? A cumulative meta-analysis. Stroke 2003; 34: 1437-1442.

24. Kleindorfer D, Lindsell CJ, Brass L, Koroshetz W, Broderick JP. National US estimates of recombinant tissue plasminogen activator use: ICD-9 codes substantially underestimate. Stroke 2008; 39: 924-928.

25. Stankowski JN, Gupta R. Therapeutic targets for neuroprotection in acute ischemic stroke: lost in translation? Antioxid Redox Signal 2011; 14: 1841-1851.

26. Yuan J. Neuroprotective strategies targeting apoptotic and necrotic cell death for stroke. Apoptosis 2009; 14: 469-477. 
27. Fisher M, Feuerstein G, Howells DW, Hurn PD, Kent TA, Savitz SI et al. Update of the stroke therapy academic industry roundtable preclinical recommendations. Stroke 2009; 40: 2244-2250.

28. Schmidt A, Minnerup J, Kleinschnitz C. Emerging neuroprotective drugs for the treatment of acute ischaemic stroke. Expert Opin Emerg Drugs 2013; 18: 109-120.

29. Puyal J, Ginet V, Clarke PG. Multiple interacting cell death mechanisms in the mediation of excitotoxicity and ischemic brain damage: a challenge for neuroprotection. Prog Neurobio 2013; 105: 24-48

30. Lai TW, Zhang S, Wang YT. Excitotoxicity and stroke: identifying novel targets for neuroprotection. Prog Neurobiol 2014; 115: 157-188.

31. Chen M, Lu TJ, Chen XJ, Zhou Y, Chen Q, Feng XY et al. Differential roles of NMDA receptor subtypes in ischemic neuronal cell death and ischemic tolerance. Stroke 2008; 39 3042-3048.

32. Jo H, Mondal S, Tan D, Nagata E, Takizawa S, Sharma AK et al. Small molecule-induced cytosolic activation of protein kinase Akt rescues ischemia-elicited neuronal death. Proc Natl Acad Sci USA 2012; 109: 10581-10586.

33. Zhang S, Taghibiglou C, Girling K, Dong Z, Lin SZ, Lee W et al. Critical role of increased PTEN nuclear translocation in excitotoxic and ischemic neuronal injuries. J Neurosci 2013 33: 7997-8008.

34. Aarts M, Liu Y, Liu L, Besshoh S, Arundine M, Gurd JW et al. Treatment of ischemic brain damage by perturbing NMDA receptor- PSD-95 protein interactions. Science 2002; 298: 846-850

35. Cook DJ, Teves L, Tymianski M. Treatment of stroke with a PSD-95 inhibitor in the gyrencephalic primate brain. Nature 2012; 483: 213-217.

36. Cook DJ, Teves L, Tymianski M. A translational paradigm for the preclinical evaluation of the stroke neuroprotectant Tat-NR2B9c in gyrencephalic nonhuman primates. Sci Transl Med 2012; 4: 154ra133.

37. Christopherson KS, Hillier BJ, Lim WA, Bredt DS. PSD-95 assembles a ternary complex with the N-methyl-D-aspartic acid receptor and a bivalent neuronal NO synthase PDZ domain. J Biol Chem 1999; 274: 27467-27473.

38. Sattler R, Xiong Z, Lu WY, Hafner M, MacDonald JF, Tymianski M. Specific coupling of NMDA receptor activation to nitric oxide neurotoxicity by PSD-95 protein. Science 1999; 284: 1845-1848.

39. Tomasi S, Sarmientos P, Giorda G, Gurewich V, Vercelli A. Mutant prourokinase with adjunctive C1-inhibitor is an effective and safer alternative to IPA in rat stroke. PLOS One 2011; 6: e21999.

40. Stetler RA, Leak RK, Gan Y, Li P, Zhang F, Hu X et al. Preconditioning provides neuroprotection in models of CNS disease: paradigms and clinical significance. Prog Neurobiol 2014; 114: 58-83

41. Queiroga CS, Tomasi S, Widerøe M, Alves PM, Vercelli A, Vieira HL. Preconditioning triggered by carbon monoxide $(\mathrm{CO})$ provides neuronal protection following perinatal hypoxiaischemia. PLoS One 2012; 7: e42632.

42. Liu X, Ye R, Yan T, Yu SP, Wei L, Xu G et al. Cell based therapies for ischemic stroke: from basic science to bedside. Prog Neurobiol 2014; 115: 92-115.

43. Haeusgen W, Herdegen T, Waetzig V. The bottleneck of JNK signaling: molecular and functional characteristics of MKK4 and MKK7. Eur J Cell Biol 2011; 90: 536-544.

44. Sanchez R, Pantoja-Uceda D, Prieto J, Diercks T, Marcaida MJ, Montoya G et al. Solution structure of human growth arrest and DNA damage 45alpha (Gadd45alpha) and its interactions with proliferating cell nuclear antigen (PCNA) and Aurora A kinase. J Biol Chem 2010; 285: 22196-22201.

45. Evans SE, Williams C, Arthur CJ, Płoskoń E, Wattana-amorn P, Cox RJ et al. Probing the Interactions of early polyketide intermediates with the Actinorhodin ACP from S. coelicolor A3 (2). J Mol Biol 2009; 389: 511-528.

46. Guex N, Peitsch MC. SWISS-MODEL and the Swiss-PdbViewer: an environment for comparative protein modeling. Electrophoresis 1997; 18: 2714-2723.

47. de Vries SJ, van Dijk M, Bonvin AM. The HADDOCK web server for data-driven biomolecular docking. Nat Protoc 2010; 5: 883-897.

48. Fields GB, Noble RL. Solid phase peptide synthesis utilizing 9-fluorenylmethoxycarbonyl amino acids. Int J Pept Protein Res 1990; 35: 161-214.

49. Carpino LA, Henklein P, Foxman BM, Abdelmoty I, Costisella B, Wray V et al. The solid state and solution structure of HAPyU. J Org Chem 2001; 66: 5245-5247.

50. Renolleau S, Aggoun-Zouaoui D, Ben-Ari Y, Charriaut-Marlangue C. A model of transient unilateral focal ischemia with reperfusion in the $\mathrm{P} 7$ neonatal rat: morphological changes indicative of apoptosis. Stroke 1998; 29: 1454-1460; discussion 1461.

51. Busch E, Krüger K, Hossmann KA. Improved model of thromboembolic stroke and rt-PA induced reperfusion in the rat. Brain Res 1997; 778: 16-24.

52. Longa EZ, Weinstein PR, Carlson S, Cummins R. Reversible middle cerebral artery occlusion without craniectomy in rats. Stroke 1989; 20: 84-91.

53. Belayev L, Alonso OF, Busto R, Zhao W, Ginsberg MD. Middle cerebral artery occlusion in the rat by intraluminal suture. Neurological and pathological evaluation of an improved model. Stroke 1996; 27: 1616-1622; discussion 1623.

54. Clark WM, Lessov NS, Dixon MP, Eckenstein F. Monofilament intraluminal middle cerebral artery occlusion in the mouse. Neurol Res 1997; 19 p 641-648.

55. Bederson JB, Pitts LH, Germano SM, Nishimura MC, Davis RL, Bartkowski HM. Evaluation of 2,3,5-triphenyltetrazolium chloride as a stain for detection and quantification of experimental cerebral infarction in rats. Stroke 1986; 17: 1304-1308.

56. Dohare P, Garg P, Jain V, Nath C, Ray M. Dose dependence and therapeutic window for the neuroprotective effects of curcumin in thromboembolic model of rat. Behav Brain Res 2008; 193 p 289-297.

(c) Cell Death and Disease is an open-access journal published by Nature Publishing Group. This work is licensed under a Creative Commons Attribution 4.0 International License. The images or other third party material in this article are included in the article's Creative Commons license, unless indicated otherwise in the credit line; if the material is not included under the Creative Commons license, users will need to obtain permission from the license holder to reproduce the material. To view a copy of this license, visit http://creativecommons.org/licenses/by/4.0/ 